\title{
Thermal Modeling and Design Optimization of PCB Vias and Pads
}

\author{
Yanfeng Shen, Member, IEEE, Huai Wang, Senior Member, IEEE, Frede Blaabjerg, Fellow, IEEE, \\ Hui Zhao, Member, IEEE, and Teng Long, Member, IEEE
}

\begin{abstract}
Miniature power semiconductor devices mounted on printed circuit boards (PCBs) are normally cooled by means of PCB vias, copper pads, and/or heatsinks. Various reference PCB thermal designs have been provided by semiconductor manufacturers and researchers. However, the recommendations are not optimal, and there are some discrepancies among them, which may confuse electrical engineers. This paper aims to develop analytical thermal resistance models for PCB vias and pads, and further to obtain the optimal design for thermal resistance minimization. Firstly, the PCB via array is thermally modeled in terms of multiple design parameters. A systematic parametric analysis leads to an optimal trajectory for the via diameter at different PCB specifications. Then an axisymmetric thermal resistance model is developed for $\mathrm{PCB}$ thermal pads where the heat conduction, convection and radiation all exist; due to the interdependence between the conductive/radiative heat transfer coefficients and the board temperatures, an algorithm is proposed to fast obtain the board-ambient thermal resistance and to predict the semiconductor junction temperature. Finally, the proposed thermal models and design optimization algorithms are verified by computational fluid dynamics (CFD) simulations and experimental measurements.
\end{abstract}

Index terms - thermal resistance model, thermal management, printed circuit board (PCB), PCB via, thermal pad.

\section{NOMENCLATURE}

\section{Bi Biot number}

$h \quad$ Heat transfer coefficient $\left(\mathrm{W} /\left(\mathrm{m}^{2} \cdot \mathrm{K}\right)\right)$

$h_{\text {conv }} \quad$ Convective heat transfer coefficient $\left(\mathrm{W} /\left(\mathrm{m}^{2} \cdot \mathrm{K}\right)\right)$

$h_{\text {radi }} \quad$ Radiative heat transfer coefficient $\left(\mathrm{W} /\left(\mathrm{m}^{2} \cdot \mathrm{K}\right)\right)$

$k \quad$ Thermal conductivity of a material $(\mathrm{W} /(\mathrm{m} \cdot \mathrm{K}))$

$k_{1} \quad$ Lateral thermal conductivity of the copper zone $\left(\mathrm{W} /\left(\mathrm{m}^{2} \cdot \mathrm{K}\right)\right)$

$k_{2} \quad$ Lateral thermal conductivity of the FR4 zone $\left(\mathrm{W} /\left(\mathrm{m}^{2} \cdot \mathrm{K}\right)\right)$

Part of this work was presented at the $10^{\text {th }}$ IEEE Energy Conversion Congress \& Expo (ECCE2018), Portland, USA, and the $29^{\text {th }}$ European Symposium on Reliability of Electron Devices, Failure Physics and Analysis (ESREF2018), Aalborg, Denmark. This work was supported by the Innovation Fund Denmark through the Advanced Power Electronic Technology and Tools (APETT) project. (Corresponding authors: Teng Long and Yanfeng Shen).

Y. Shen, H. Zhao and T. Long are with the Department of Engineering-Electrical Engineering Division, University of Cambridge, Cambridge CB3 0FA, United Kingdom (e-mail: ys523@cam.ac.uk,hz352@cam.ac.uk, t1322@cam.ac.uk)

H. Wang, and F. Blaabjerg are with the Center of Reliable Power Electronics (CORPE), Department of Energy Technology, Aalborg University, Aalborg 9220, Denmark (e-mail: hwa@et.aau.dk, fbl@et.aau.dk).
$k_{C u} \quad$ Thermal conductivity of copper $\left(\mathrm{W} /\left(\mathrm{m}^{2} \cdot \mathrm{K}\right)\right)$

$k_{F R 4} \quad$ Thermal conductivity of FR4 $\left(\mathrm{W} /\left(\mathrm{m}^{2} \cdot \mathrm{K}\right)\right)$

$k_{\text {filler }} \quad$ Thermal conductivity of via filling material $\left(\mathrm{W} /\left(\mathrm{m}^{2} \cdot \mathrm{K}\right)\right)$

$l \quad$ Length of a via array (m)

$L_{c} \quad$ Characteristic length of a hot plate (m)

$m_{1} \quad$ Number of rows of a via array in Pattern I

$m_{2} \quad$ Number of rows of a via array in Pattern II

$n_{1} \quad$ Number of columns of a via array in Pattern I

$n_{2} \quad$ Number of columns of a via array in Pattern II

$N_{C u} \quad$ Number of copper layers in a PCB

$P \quad$ Power loss generated by a heat source (W)

$q \quad$ Heat flux $\left(\mathrm{W} / \mathrm{m}^{2}\right)$

$r_{b} \quad$ Radius of heat source (package) $(\mathrm{m})$

$r_{s} \quad$ Radius of middle (copper) zone $(\mathrm{m})$

$r_{e} \quad$ Radius of outer (FR4) zone (m)

$s \quad$ Via-to-via spacing (m)

$t \quad$ PCB thickness(m)

$t_{C u} \quad$ Thickness of a PCB copper layer (m)

$t_{P T H} \quad$ Plating thickness of PCB vias (m)

$T_{b} \quad$ PCB board $\left(r=r_{b}\right)$ temperature $\left({ }^{\circ} \mathrm{C}\right)$

$T_{c} \quad$ Case temperature of a package (chip) $\left({ }^{\circ} \mathrm{C}\right)$

$T_{j} \quad$ Junction temperature of a chip $\left({ }^{\circ} \mathrm{C}\right)$

$T_{t} \quad$ Top case temperature of a package (chip) $\left({ }^{\circ} \mathrm{C}\right)$

$T_{a} \quad$ Ambient temperature $\left({ }^{\circ} \mathrm{C}\right)$

$w \quad$ Width of a via array (m)

$\varepsilon \quad$ Emissivity of PCB surface

$\Theta_{b a} \quad$ Thermal resistance from the inner zone edge $\left(r=r_{b}\right)$ to the ambient $\left({ }^{\circ} \mathrm{C} / \mathrm{W}\right)$

$\Theta_{\text {barrel }}$ Vertical thermal resistance of the copper barrel in a via unit $\left({ }^{\circ} \mathrm{C} / \mathrm{W}\right)$

$\Theta_{c b}$ Thermal resistance from the case to the PCB $\left(r=r_{b}\right)$ $\left({ }^{\circ} \mathrm{C} / \mathrm{W}\right)$

$\Theta_{\text {unit }} \quad$ Vertical thermal resistance of a via unit $\left({ }^{\circ} \mathrm{C} / \mathrm{W}\right)$

$\Theta_{C u} \quad$ Vertical thermal resistance of the copper layers in a via unit $\left({ }^{\circ} \mathrm{C} / \mathrm{W}\right)$

$\Theta_{\text {filler }}$ Vertical thermal resistance of the filler in a via unit $\left({ }^{\circ} \mathrm{C} / \mathrm{W}\right)$

$\Theta_{F R 4}$ Vertical thermal resistance of the FR4 layers in a via unit $\left({ }^{\circ} \mathrm{C} / \mathrm{W}\right)$

$\Theta_{j c} \quad$ Thermal resistance from the junction to the case $\left({ }^{\circ} \mathrm{C} / \mathrm{W}\right)$

$\Theta_{j t} \quad$ Thermal resistance from the junction to the top case $\left({ }^{\circ} \mathrm{C} / \mathrm{W}\right)$

$\Theta_{r, i j} \quad$ Radial thermal resistance between outer-zone via layers $\left({ }^{\circ} \mathrm{C} / \mathrm{W}\right)$

$\Theta_{s a} \quad$ Thermal resistance from the copper zone edge $\left(r=r_{s}\right)$ to the ambient $\left({ }^{\circ} \mathrm{C} / \mathrm{W}\right)$ 
$\Theta_{t a}$ Thermal resistance from the top case of the chip to the ambient $\left({ }^{\circ} \mathrm{C} / \mathrm{W}\right)$

$\Theta_{\text {via }} \quad$ Vertical thermal resistance of a via array $\left({ }^{\circ} \mathrm{C} / \mathrm{W}\right)$

$\Theta_{v i a, n} \quad$ Normalized vertical thermal resistance of a via array

$\Theta_{v, i j} \quad$ Vertical thermal resistance between copper layers of outer-zone vias $\left({ }^{\circ} \mathrm{C} / \mathrm{W}\right)$

$\lambda$ Convective heat transfer parameter depending on PCB geometry and orientation

$\sigma \quad$ Stefan-Boltzmann constant $\sigma=5.670367 \times 10^{-8}$ $\left(\mathrm{W} \cdot \mathrm{m}^{-2} \cdot \mathrm{K}^{-4}\right)$

$\tau \quad$ Time (s)

$\phi \quad$ Via diameter (m)

$\phi_{o p t} \quad$ Optimal via diameter (m)

$\psi_{e a} \quad$ Equivalent thermal resistance from the FR4 zone edge $\left(r=r_{e}\right)$ to the ambient $\left({ }^{\circ} \mathrm{C} / \mathrm{W}\right)$

$\psi_{s a} \quad$ Equivalent thermal resistance from the copper zone edge $\left(r=r_{s}\right)$ to the ambient $\left({ }^{\circ} \mathrm{C} / \mathrm{W}\right)$

$\psi_{t a} \quad$ Equivalent thermal resistance from the top case of a package to the ambient $\left({ }^{\circ} \mathrm{C} / \mathrm{W}\right)$

\section{INTRODUCTION}

The volume of modern power semiconductor devices (e.g., $\mathrm{GaN}$ transistors) are continuingly shrinking in order to achieve higher power densities, lower parasitic inductances, and lower power losses [1]-[3]. However, thermal management has been identified as the main barrier for further power density increase [4]. The heat generated inside the miniaturized semiconductors must be effectively dissipated to the ambient; otherwise, the high junction and board temperatures may cause serious reliability issues to the semiconductor, solder, thermal grease, and printed circuit board (PCB) [5]-[8]. In addition, suitable heat dissipation measures should be considered as early as in the design and development phase, because subsequent modifications are generally more costly and involve increased engineering effort [9], [10].

In medium power applications, the surface-mounted devices (SMDs) are normally cooled by a heatsink attached to the PCB, where the thermal via array provides an effective thermal path for the heat transfer [11]-[13]. In low power scenarios, a PCB copper pad is typically used for heat spreading, and the SMD can be cooled by natural convection [14]. Many reference thermal designs can be found from device manufacturers' websites [14]-[18]. However, several problems remain:

1) the thermal design guidelines recommended by manufacturers are not optimal, and they are applicable for specific packages only [15], [16];

2) inconsistent guidelines; for instance, the thermal via diameter should be designed as large to reduce the thermal resistance according to [16]; however, [15], [17] and [18] recommend smaller via diameters and adopt different via pitches.

Although the computational fluid dynamics (CFD) simulations feature high accuracy, the model generation time and computational cost could be fairly high [14]. Moreover, CFD simulators are expensive and they are not always available for electrical engineers. Therefore, it is necessary to develop analytical models which enable fast and accurate design optimization for thermal vias and pads.
In the literature, many efforts have been devoted to the optimization of PCB thermal vias. The research in [19]-[21] is based on either experimental results or CFD simulations; thus, not all design scenarios are explored, but only some general design guidelines are provided for specific applications. Analytical thermal models of vias are built in [11], [22]-[25]; unfortunately, only partial parameters are analyzed, and no optimal via design is derived.

For the PCB heat transfer characteristics, the heat conduction, convection and radiation all exist, which makes the thermal analysis complicated. Texas Instruments have developed an online PCB thermal calculation tool based on CFD thermal resistance data of different package sizes and pad dimensions [26]. However, some important factors (e.g., the PCB thickness, number of copper layers, and copper thickness) are not taken into account, and also the online tool does not support design optimization. In addition to the CFD simulations, some other numerical calculation methods are developed [27], [28]. The study in [28] deals with a substrate for a ball grid array package, where a belt of densely populated vias and two continuous copper layers are placed; however, the model is complicated and no CFD or experimental verifications are provided. For electrical engineers, it is more desirable to have an analytical thermal model such that the temperatures of devices with different designs and cooling methods can be fast predicted [29], [30]. In [14] and [31], an analytical thermal resistance model is developed for PCB thermal pads; however, the heat transfer boundary and the convective heat transfer coefficient variation over the temperature difference are not included, causing potential errors between calculations and measurements.

This paper proposed two new analytical thermal models for PCB vias and thermal pads, respectively. For the thermal model of PCB vias, a systematic parametric analysis is firstly conducted, which leads to a simplified thermal resistance model. An optimal design trajectory is then obtained for PCB vias with different specifications. After that, an analytical axisymmetric thermal resistance model is proposed for PCB thermal pads. Taking into account the interdependence between the convection/radiative heat transfer coefficients and board temperatures, a simple algorithm is developed to size thermal pads at different PCB parameters, power losses, ambient temperatures, and allowed maximum junction temperatures. Finally, CFD simulations and experimental measurements verify the developed analytical thermal models. The proposed models enable electrical engineers to optimize their PCB via design and thermal pad sizing at lower cost and less time effort.

\section{Thermal Modeling AND Design Optimization OF PCB VIAS}

\section{A. Thermal Modeling of PCB Vias}

A cluster of PCB plated through holes (PTHs), i.e., vias, can provide an effective thermal path, which helps to transfer heat from an SMD (chip) to a heatsink. The vertical structure of a multilayer PCB with vias is shown in Fig. 1(a). The via diameter, via-to-via spacing, and via plating thickness are denoted as $\phi, s$, and $t_{P T H}$, respectively. The number of copper layers and the copper layer thickness are represented by $N_{C u}$ and $t_{C u}$, respectively. 
For the layout of vias, there are various uniform and nonuniform design options. For the sake of simplicity, this paper focuses on two simple uniform patterns, denoted as Pattern I and Pattern II, as illustrated in Fig. 1(b) and (c), respectively. However, the derived method can be applied to other vias layout with minor modifications. The length, width, and thickness of the PCB via array are denoted as $l, w$, and $t$, respectively. Normally, the PCB thickness is much smaller than its length and width. Also, the attached heatsink has a large heat dissipation capability. Therefore, it is assumed that the heat generated inside the SMD is transferred in the vertical direction only. Accordingly, the PCB via array in each pattern can be divided into multiple via units, as indicated by the dashed box in Fig. 1. It is seen from the horizontal cross-sections of the via array that the basic via unit in Pattern I is a square of $(\phi+s) \times$ $(\phi+s)$, whereas that in Pattern II is rectangular with $[\sqrt{3}(\phi+$ $s) / 2] \times(\phi+s)$. If the PCB via array size $(l$ and $w)$ and via parameters $(\phi$ and $s)$ are fixed, and the array parameters $(l$ and $w)$ are much larger than the via unit parameters $(\phi$ and $s)$, then the numbers of vias that Patterns I and II can accommodate are calculated as

$$
\left\{\begin{array}{rlr}
m_{1} \times n_{1} & =\text { floor }[l /(\phi+s)] \times \text { floor }[w /(\phi+s)] \\
& \approx l w /\left[(\phi+s)^{2}\right], & \text { Pattern I } \\
m_{2} \times n_{2} & =\text { floor }[l /(\phi+s)] \times \text { floor }\{2 w /[\sqrt{3}(\phi+s)]\} \\
& \approx 2 l w /\left[\sqrt{3}(\phi+s)^{2}\right], & \text { Pattern II }
\end{array}\right.
$$

It is seen from (1) that Pattern II can accommodate approximately $2 / \sqrt{3}-1=15.5 \%$ more vias than Pattern I.

As can be seen from Fig. 1, there are three vertical thermal paths for each via unit, i.e., the via filler, the via barrel, and the copper and flame retardant 4 (FR4) layers, whose vertical thermal resistances are represented by $\Theta_{\text {barrel }}, \Theta_{\text {filler }}$, and $\Theta_{C u}+$ $\Theta_{F R 4}$, respectively, as below

$$
\begin{aligned}
& \Theta_{\text {filler }}=\frac{t}{k_{\text {filler }} \pi\left(\phi / 2-t_{P T H}\right)^{2}}, \\
& \Theta_{\text {barrel }}=\frac{t}{k_{C u} \pi t_{P T H}\left(\phi-t_{P T H}\right)}, \\
& \Theta_{C u}+\Theta_{F R 4}=\left(\frac{N_{C u} t_{C u}}{k_{C u}}+\frac{t-N_{C u} t_{C u}}{k_{F R 4}}\right) \\
& \times \begin{cases}\frac{1}{(\phi+s)^{2}-\pi \phi^{2} / 4}, & \text { Pattern I } \\
\frac{1}{\sqrt{3}(\phi+s)^{2} / 2-\pi \phi^{2} / 4}, & \text { Pattern II }\end{cases} \\
& \Theta_{\text {unit }}=\Theta_{\text {filler }}\left\|\Theta_{\text {barrel }}\right\|\left(\Theta_{C u}+\Theta_{F R 4}\right)
\end{aligned}
$$

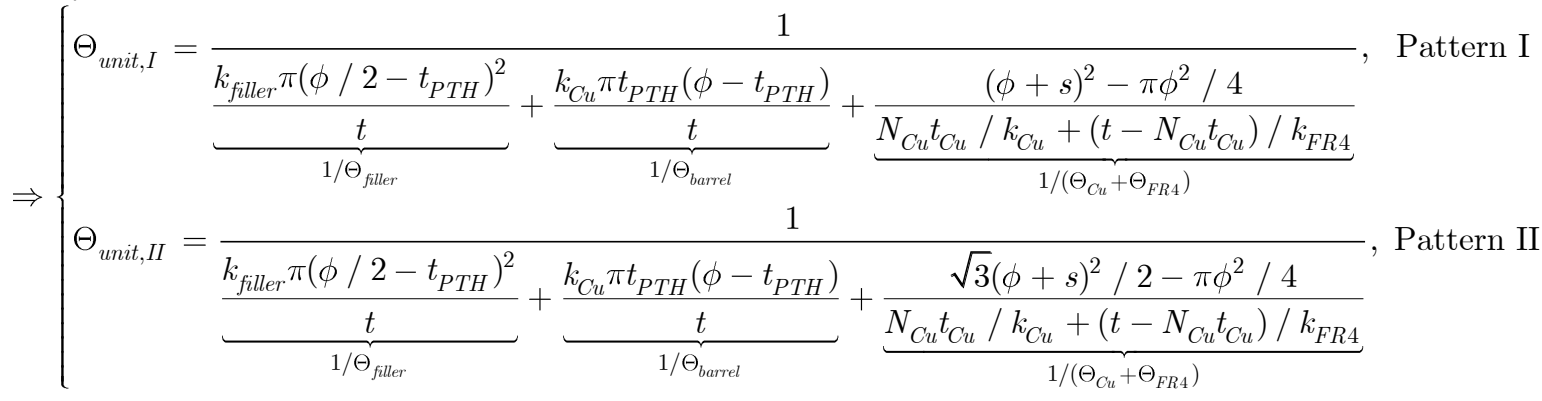


From the perspective of vertical heat transfer, the via units are equivalently connected in parallel, and therefore the total vertical thermal resistances of a via array of $l \times w \times t$ can be obtained as

$$
\Theta_{v i a}=\left\{\begin{array}{l}
\frac{\Theta_{\text {unit }, I}}{m_{1} \times n_{1}}, \text { Pattern I } \\
\frac{\Theta_{\text {unit }, I I}}{m_{2} \times n_{2}}, \text { Pattern II }
\end{array}\right.
$$

To simplify the following theoretical analysis, the thermal resistance of a via array is normalized based on the thermal resistance of an FR4 pad with the same size $(l \times w \times t)$, yielding (5).

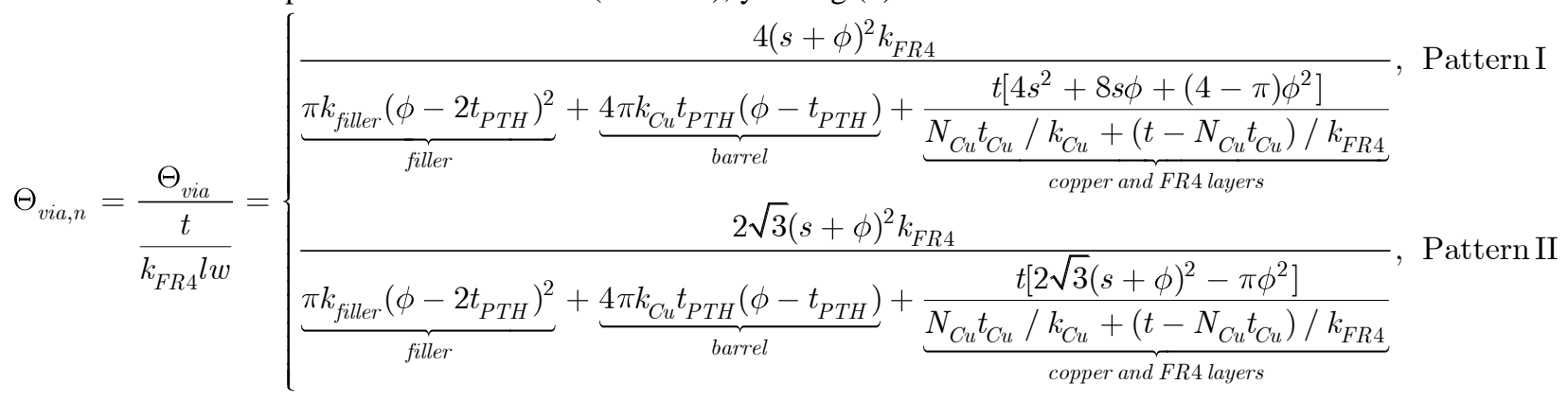

\section{B. Parametric Analysis and Design Optimization of $P C B$ Vias}

TABLE I

THERMAL CONDUCTIVITIES OF MATERIALS AT $25^{\circ} \mathrm{C}$ [33]-[36]

\begin{tabular}{cccccc}
\hline \hline \multirow{2}{*}{ Material } & \multirow{2}{*}{ Copper } & \multirow{2}{*}{$\begin{array}{c}\mathrm{SnAgCu} \\
\text { solder }\end{array}$} & $\begin{array}{c}\text { Through- } \\
\text { plan }\end{array}$ & In-plane & $\begin{array}{c}\text { Air at } \\
\text { atmospheric } \\
\text { pressure }\end{array}$ \\
\hline $\begin{array}{c}\text { Thermal } \\
\text { conductivity }\end{array}$ & $\begin{array}{c}393 \\
\mathrm{~W} /(\mathrm{m} \cdot \mathrm{K})\end{array}$ & $\begin{array}{c}57.3 \\
\mathrm{~W} /(\mathrm{m} \cdot \mathrm{K})\end{array}$ & $\begin{array}{c}0.29 \\
\mathrm{~W} /(\mathrm{m} \cdot \mathrm{K})\end{array}$ & $\begin{array}{c}0.81 \\
\mathrm{~W} /(\mathrm{m} \cdot \mathrm{K})\end{array}$ & $\begin{array}{c}0.026 \\
\mathrm{~W} /(\mathrm{m} \cdot \mathrm{K})\end{array}$ \\
\hline \hline
\end{tabular}

Since multiple design variables are included in the thermal resistance model, it is difficult to directly apply (5) in practical design optimization. Hence, it is necessary to conduct a parametric analysis on (5).

The thermal conductivity of a material is a measure of its ability to conduct heat. It is evaluated primarily in terms of the Fourier's law for heat conduction. The general equation for thermal conductivity is [32] $k=-q / \nabla T$, where $q$ is the heat flux $\left(\mathrm{W} / \mathrm{m}^{2}\right)$ and $\nabla T$ represents the temperature gradient $(\mathrm{K} / \mathrm{m})$. The thermal conductivities of the materials used in this paper are listed in Table I. The standard IPC6012 specifies a minimum copper plating thickness of $20 \mu \mathrm{m}$ for Class 1 PCBs, and $25 \mu \mathrm{m}$ is a standard via plating thickness [37]. Thus, $t_{P T H}=25 \mu \mathrm{m}$ is used in the following analysis.

\section{1) Via-to-Via Spacing $s$}

Based on (5), the curves of the normalized via thermal resistance with respect to the via-to-via spacing $s$ can be depicted for different filler materials, PCB thicknesses, and via diameters, as shown in Fig. 2. It is seen that the normalized via thermal resistance $\Theta_{v i a, n}$ always rises when the via-to-via spacing $s$ increases, regardless of the PCB thickness, via filling material and via diameter. Therefore, $s$ should be designed as small as possible in order to reduce the thermal resistance of PCB via array. In practice, however, the allowed minimum via-to-via spacing depends on PCB manufacturing capability and is cost sensitive. Generally, 8 mil $(0.2 \mathrm{~mm})$ is a commonly-specified minimum via-to-via spacing by most PCB manufacturers, and therefore, $s=0.2$ $\mathrm{mm}$ is used in the following analysis and experiments.

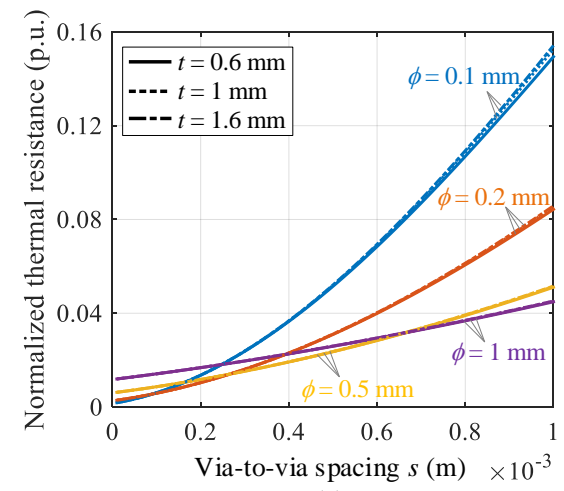

(a)

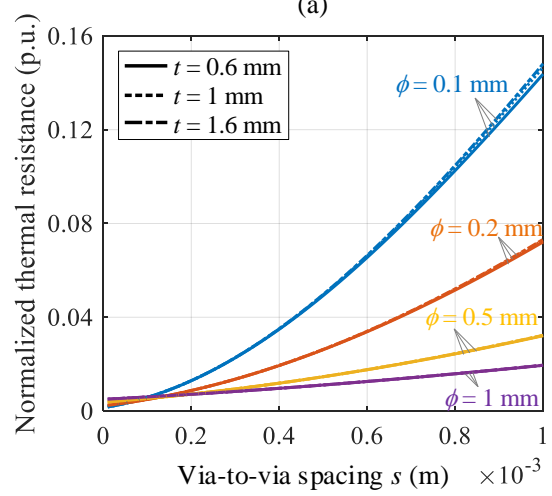

(b)

Fig. 2. Dependence of the normalized thermal resistance of via array in Pattern $I$ on the via-to-via spacing $s$ with two via filling materials: (a) air with a thermal conductivity of $0.026 \mathrm{~W} /(\mathrm{m} \cdot \mathrm{K})$, and (b) solder with a thermal conductivity of $57.3 \mathrm{~W} /(\mathrm{m} \cdot \mathrm{K})$. 


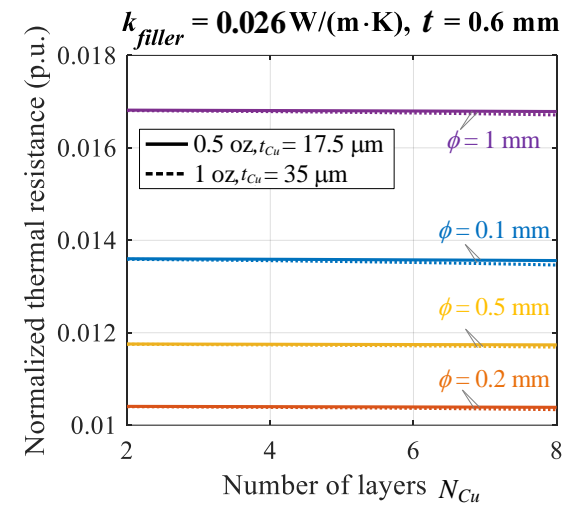

(a)

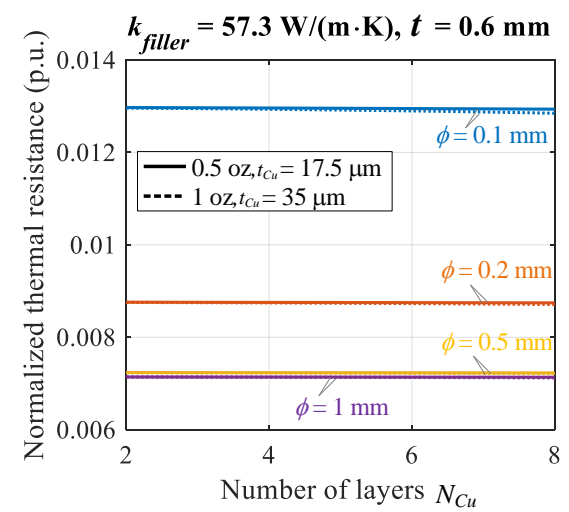

(d)

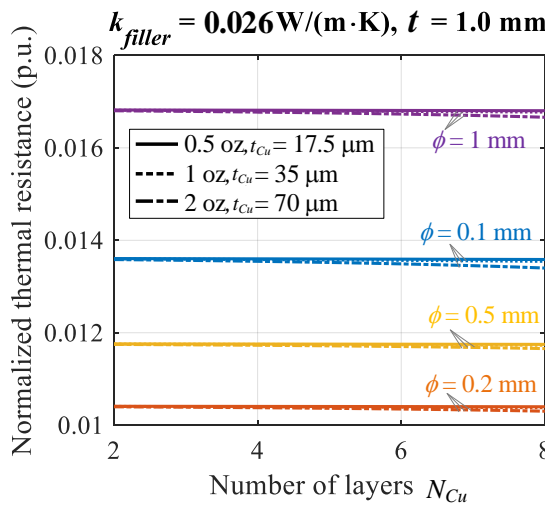

(b)

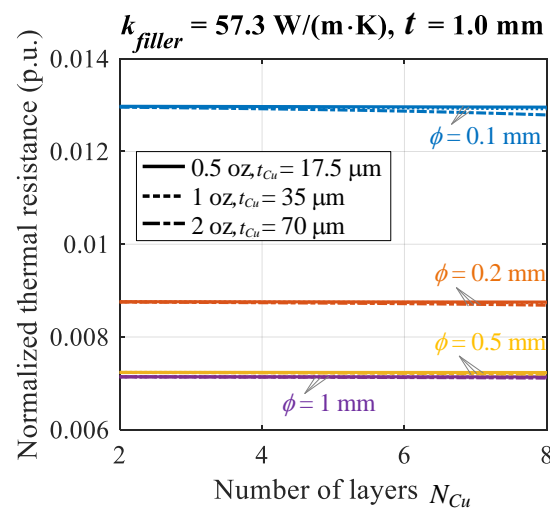

(e)

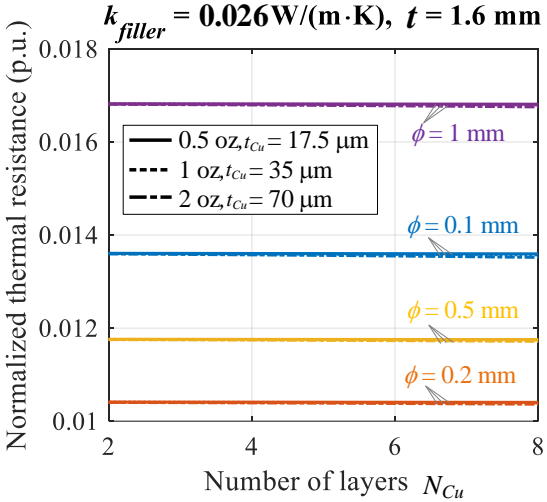

(c)

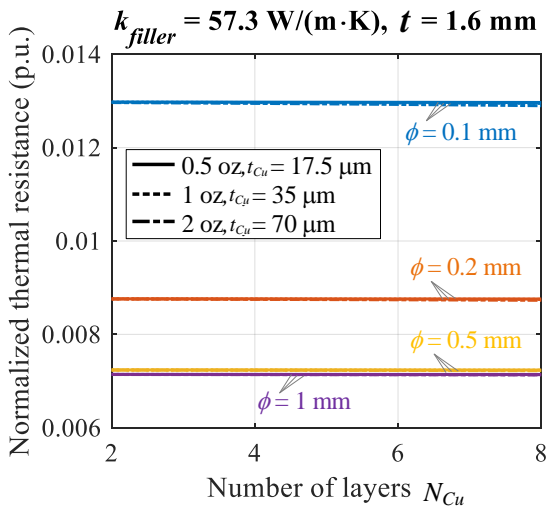

(f)

Fig. 3. Dependence of the normalized thermal resistance of via array in Pattern I on the number of copper layers $N_{C u}$, copper thickness $t_{C u}$, and PCB thickness $t$ with different via filling materials. (a) Air with thermal conductivity $k_{\text {filler }}=0.026 \mathrm{~W}(\mathrm{~m} \cdot \mathrm{K}$ ) and PCB thickness $t=0.6 \mathrm{~mm}$; (b) Air with thermal conductivity $k_{\text {filler }}=0.026 \mathrm{~W}(\mathrm{~m} \cdot \mathrm{K})$, PCB thickness $t=1.0 \mathrm{~mm}$; (c) Air with thermal conductivity $k_{\text {filler }}=0.026 \mathrm{~W}(\mathrm{~m} \cdot \mathrm{K})$, PCB thickness $t=1.6 \mathrm{~mm}$; (d) Solder with thermal conductivity $k_{\text {filler }}=57.3 \mathrm{~W}(\mathrm{~m} \cdot \mathrm{K})$, PCB thickness $t=0.6 \mathrm{~mm}$; (e) Solder with thermal conductivity $k_{\text {filler }}=57.3 \mathrm{~W}(\mathrm{~m} \cdot \mathrm{K})$, PCB thickness $t=1.0 \mathrm{~mm}$; (f) Solder with thermal conductivity $k_{\text {filler }}=57.3 \mathrm{~W}(\mathrm{~m} \cdot \mathrm{K}), \mathrm{PCB}$ thickness $t=1.6 \mathrm{~mm}$.

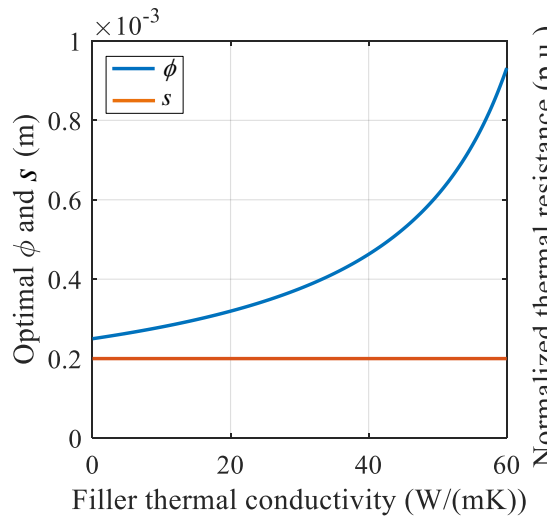

(a)

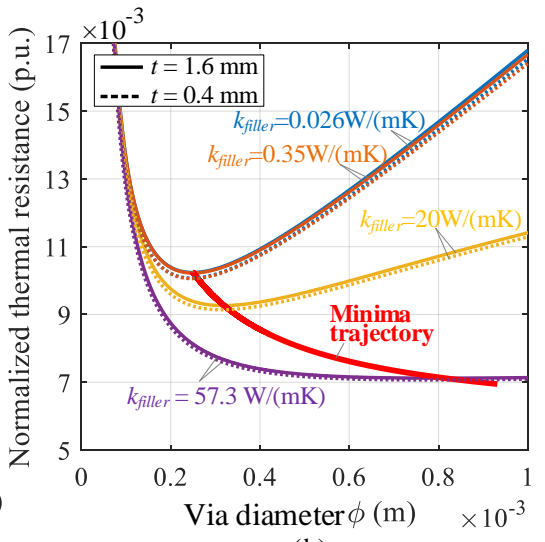

(b)

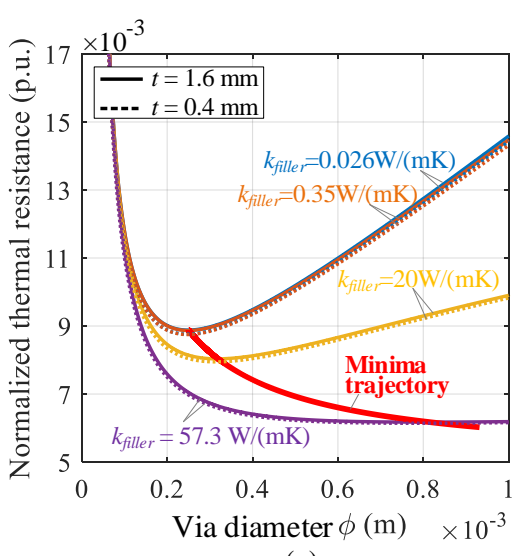

(c)

Fig. 4. (a) Optimal trajectories of via diameter $\phi$ and via-to-via spacing $s$ with respect to the filler thermal conductivity. Dependence of the normalized thermal resistance of via array on the diameter $\phi$ at different PCB thicknesses and filler thermal conductivities for (b) Pattern I and (c) Pattern II.

2) Number of layers $N_{C u}, P C B$ Thickness $t$, and Copper Layer Thickness $t_{C u}$

The dependence of the normalized thermal resistance of a PCB via array, $\Theta_{v i a, n}$, on the number of copper layers $N_{C u}$, copper thickness $t_{C u}$, and PCB thickness $t$ is shown in Fig. 3. As can be seen, the parameters $N_{C u}, t_{C u}$ and $t$, have a negligible impact on the normalized thermal resistance, implying that the copper and FR4 layers have a much higher thermal resistance compared to the vias. Thus the heat is mainly transferred through the vias, and (5) can be simplified as

$$
\Theta_{v i a, n} \approx\left\{\begin{array}{r}
\frac{4(s+\phi)^{2} k_{F R 4}}{4 \pi k_{C u} t_{P T H}\left(\phi-t_{P T H}\right)+\pi k_{\text {filler }}\left(\phi-2 t_{P T H}\right)^{2}}, \\
\text { Pattern I }(6) \\
\frac{2 \sqrt{3}(s+\phi)^{2} k_{F R 4}}{4 \pi k_{C u} t_{P T H}\left(\phi-t_{P T H}\right)+\pi k_{\text {filler }}\left(\phi-2 t_{P T H}\right)^{2}}, \\
\text { Pattern II }
\end{array}\right.
$$




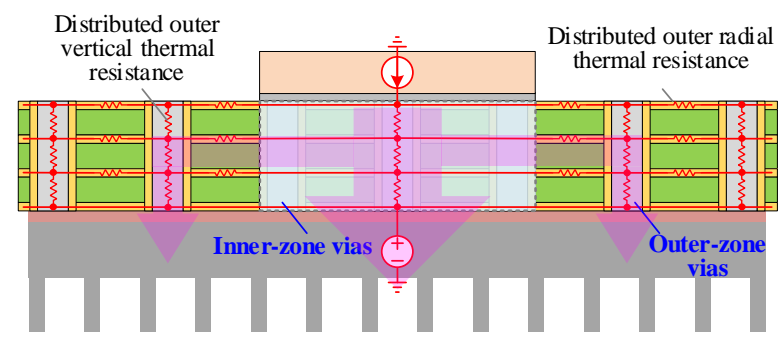

(a)

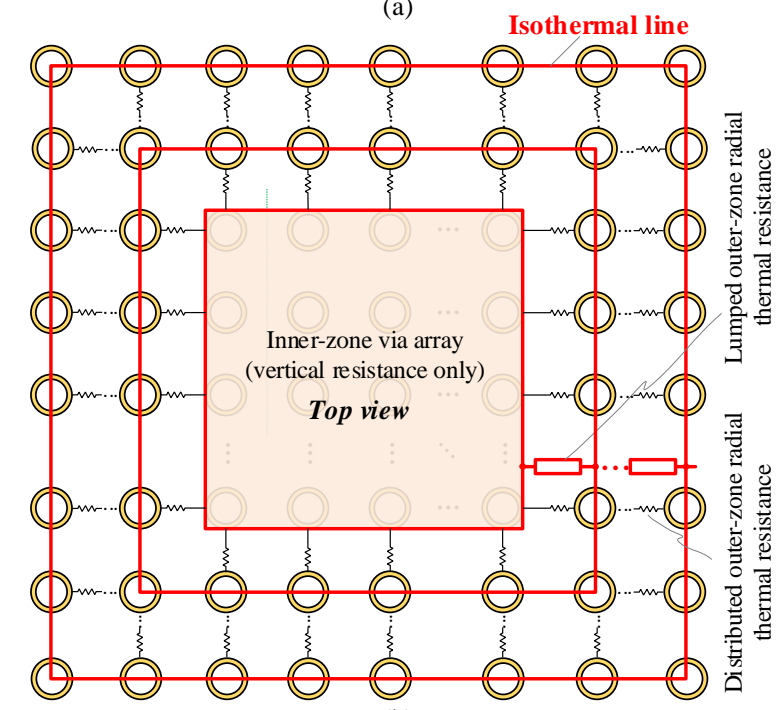

(b)

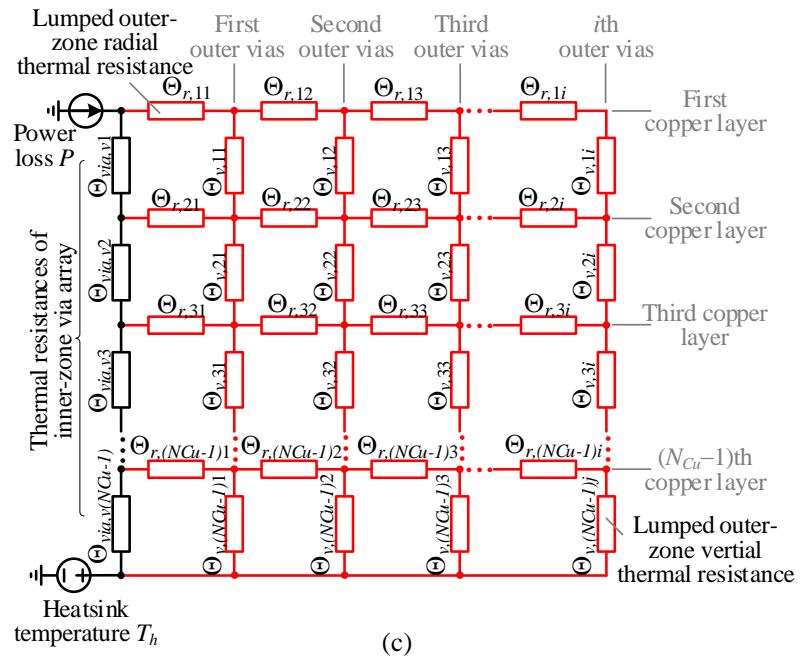

temperature $T_{h}$

(c)

Fig. 5. Thermal resistances of outer-zone vias. (a) Vertical structure of a multilayer PCB with both inner- and outer-zone vias and a large heatsink. (b) Top view of inner- and outer-zone vias. The red lines represents the isothermal lines, and the distributed outer-zone radial thermal resistances are lumped together. (c) Equivalent thermal resistance network of the PCB with both inner- and outer-zone vias.

With the same area for the via array, the thermal resistance of Pattern II is about $\sqrt{3} / 2=86.6 \%$ of that in Pattern I. From (6), we can also obtain the optimal via diameter for both patterns, which can achieve the minimum thermal resistance, i.e.,

$\phi_{\text {opt }}=\frac{2 t_{P T H}\left(s+2 t_{P T H}\right)\left(k_{C u}-k_{\text {filler }}\right)}{2 t_{P T H}\left(k_{C u}-k_{f i l l e r}\right)-k_{\text {filler }} s}$, Patterns I \& II
According to (7), the optimal trajectory of the via diameter $\phi$ with respect to the filler thermal conductivity can be depicted, as shown in Fig. 4(a). Then, the dependence of the normalized thermal resistance on the via diameter $\phi$ and the filler material is illustrated in Fig. 4(b) and (c). For each filler material, there is an optimal via diameter which can achieve the minimum thermal resistance; the minima trajectories are also depicted in Fig. 4. When the vias are not filled, the optimal via diameter is about $0.25 \mathrm{~mm}$; if $\phi=0.8 \mathrm{~mm}$ is chosen, then there will be a $44 \%$ increase in the thermal resistance. When the vias are filled up with $\mathrm{SnAgCu}$ solder $\left(k_{\text {filler }}=57.3 \mathrm{~W} / \mathrm{mK}\right)$, then the optimal via diameter is about $0.8 \mathrm{~mm}$; if $\phi=0.2 \mathrm{~mm}$ is chosen, then there will be a $23 \%$ increase in the thermal resistance.

Ref [16] uses $\mathrm{SnAgCu}$ solder as the filler material of vias, and therefore recommends large via diameters. By contrast, [15], [17] and [18] recommend smaller via diameters $(0.3$ $\mathrm{mm}, 0.2 \mathrm{~mm}$, and $0.33 \mathrm{~mm}$, respectively) for unfilled vias. Also, the via-to-via spacing values in [15], [17] and [18] are designed as $0.34 \mathrm{~mm}, 1 \mathrm{~mm}$, and $0.34 \mathrm{~mm}$, respectively. Compared with the recommended designs in [15], [17] and [18], the thermal resistance of a via array with the proposed optimal trajectories (see Fig. 4) can be reduced by $47 \%$, $89.5 \%$, and $46.4 \%$, respectively.

\section{Modeling of Outer-Zone Vias}

In some cases, the heatsink is larger than the chip, and thus the outer-zone vias can be added around the inner via array to further decrease the equivalent thermal resistance between the case and the heatsink, as shown in Fig. 5. For the sake of simplicity, only via Pattern I is considered herein. The PCB vias can be divided into two zones, i.e., the inner-zone via array directly beneath the chip, and the outer-zone vias around the inner-zone via array, as illustrated in Fig. 5(a) and (b).

\section{1) Lumped Thermal Resistance Model}

Since there is a uniform heat source on the inner via array, and a powerful heatsink beneath the PCB, the radialdirection heat transfer of the inner-zone via array is not pronounced compared with the vertical direction. Therefore, only the vertical thermal resistance is considered for the inner-zone via array, and it is divided into $N_{C u}-1$ parts which represent the thermal resistances between the $N_{C u}$ copper layers. As for the outer-zone vias, the radial and vertical heat transfers are equally pronounced. Hence, both the distributed radial and vertical thermal resistances are taken into account, as shown in Fig. 5(a).

It is assumed that the lateral boundary of the inner-zone via array is isothermal. Also, multilayer outer-zone vias are evenly placed around the inner-zone via array, as shown in Fig. 5(b). It implies that each layer (in the radial direction) of the outer-zone vias can be also regarded isothermal, as indicated by the red lines in Fig. 5(b). Then the distributed outer radial and vertical thermal resistances can be lumped together, yielding an equivalent thermal resistance network, as shown in Fig. 5(c).

By applying the similar principle as in Section II-A, the lumped outer-zone radial and vertical thermal resistances, i.e., $\Theta_{r, i j}$ and $\Theta_{v, i j}$, can be obtained as 


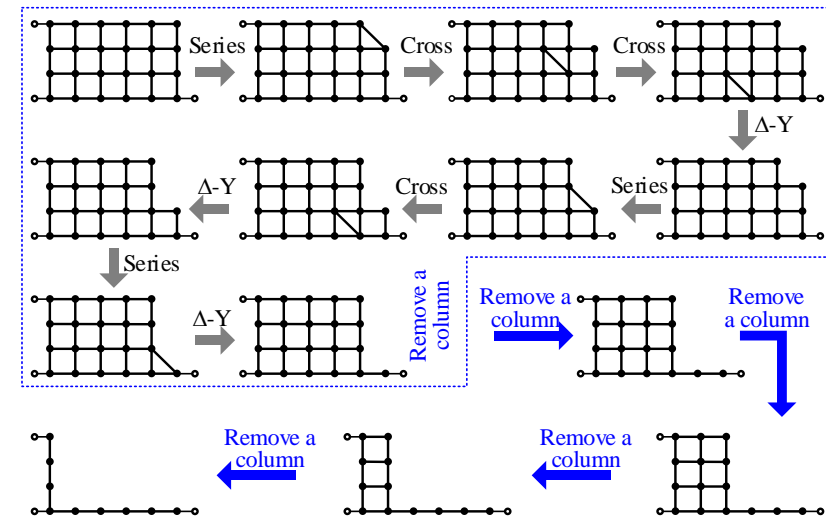

Fig. 6. Simplification of a three-terminal thermal resistance grid network. Each thick solid line represents a resistor. The terms "Series", " $\Delta-Y$ " and "Cross" represent the series transformation, $\Delta$-Y transformation, and cross transformation of resistor network, respectively.

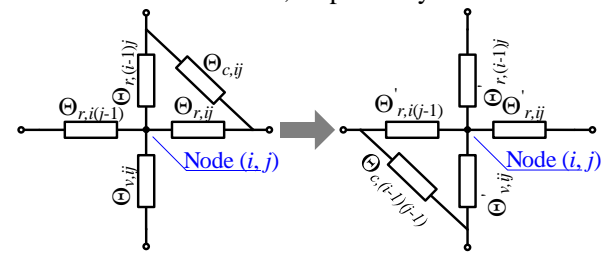

Fig. 7. Schematic of the cross transformation of a four-terminal resistor network unit. The cross transformation can be decoupled into a $\Delta$-Y transformation and a Y- $\Delta$ transformation. $\Theta_{r, i(j-1)}, \Theta_{r, i j}, \Theta_{v,(i-1) j}, \Theta_{v, i j}$ and $\Theta_{c, i j}$ represent the original thermal resistance, whereas $\Theta_{r, i(j-1)}^{\prime}, \Theta_{r, i j}^{\prime}, \Theta_{v,(i-1) j}^{\prime}, \Theta_{v, i j}^{\prime}$ and $\Theta_{c,(i-1)(j-1)}$ denote the corresponding thermal resistances after the cross transformation.

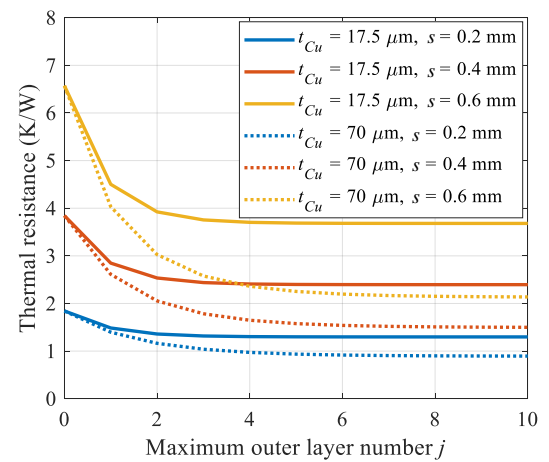

(a)

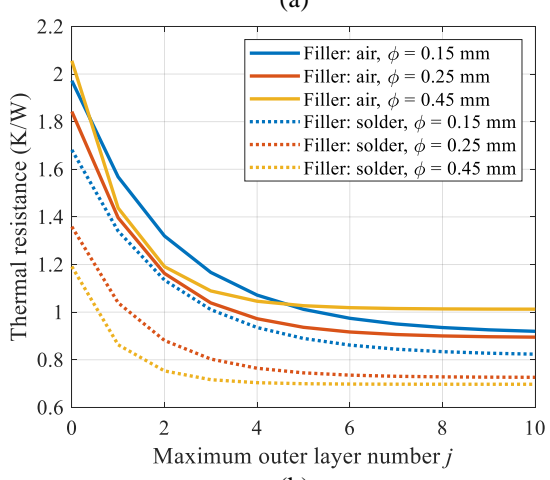

(b)

Fig. 8. Characteristics of thermal resistance of PCB vias with respect to the maximum layer number $j$ of outer-zone vias at different parameters. The PCB length $l=5.6 \mathrm{~mm}$, width $w=5.6 \mathrm{~mm}$, thickness $t=1.6 \mathrm{~mm}$, and the number of copper layers $N_{C u}=4$. (a) Fixed parameters: via diameter $\phi=$ $0.25 \mathrm{~mm}$, and filler material is air; variables: copper layer thickness $t_{C u}$, viato-via spacing $s$, and the maximum outer layer number $j$. (b) Fixed parameters: $t_{C u}=70 \mu \mathrm{m}, s=0.2 \mathrm{~mm}$; variables: filler material, via diameter $\phi$, and the maximum outer layer number $j$.

$$
\left\{\begin{aligned}
\Theta_{r, i j} & =\frac{\phi+s}{k_{C u} t_{C u}[2(l+w)+4(2 j-1)(\phi+s)]} \\
\Theta_{v, i j} & =\frac{4\left(t_{C u}+t_{F R 4}\right)\left(\frac{2(l+w)}{\phi+s}+4(2 j-1)\right)^{-1}}{\pi k_{f i l l e r}\left(\phi-2 t_{P T H}\right)^{2}+4 k_{C u} t_{P T H}\left(\phi-t_{P T H}\right)}
\end{aligned}\right.
$$

where $i$ represents the copper layer order, and $j$ denotes the outer via layer order.

Meanwhile, it is observed from (8) that both the radial and vertical outer-zone thermal resistances are functions of $j$, implying the two types of thermal resistances vary with respect to the outer via layer number. Therefore, the thermal resistances of the network shown in Fig. 5(c) are not identical.

\section{2) Derivation of Equivalent Thermal Resistance}

The equivalent thermal resistance of the complicated network shown in Fig. 5(c) can be derived by performing analog circuit simulations with given radial and vertical thermal resistance values as (8). However, there are multiple design variables (e.g., $\phi, s, j)$ and system parameters $\left(l, w, t_{C u}\right.$, $k_{\text {filler }}, t_{P T H}, N_{C u}, t$ ), which implies that the method of circuit simulation does not support systematical parametric analysis. Hence, a simplification method consisting of various steps of network transformations is proposed to derive the equivalent thermal resistance of Fig. 5(c), as illustrated in Fig. 6. Apart from the basic series and $\Delta-Y$ transformations, a new transformation termed as cross transformation is introduced in this paper, as shown in Fig. 7. The cross transformation can be decoupled into a $\Delta$-Y transformation and a Y- $\Delta$ transformation. As shown in Fig. 7, the resulting resistances after a cross transformation can be expressed by

$$
\begin{aligned}
& \left\{\begin{array}{l}
\Theta_{r, i j}^{\prime}=\frac{\Theta_{r, i j} \Theta_{c, i j}}{\Theta_{r, i j}+\Theta_{v, i j}+\Theta_{c, i j}}, \\
\Theta_{v, i j}^{\prime}=\frac{\Theta_{v, i j} \Theta_{c, i j}}{\Theta_{r, i j}+\Theta_{v, i j}+\Theta_{c, i j}} \\
\Theta_{r, i(j-1)}^{\prime}=\Theta_{r, i(j-1)}+\Theta_{o}\left(1+\Theta_{r, i(j-1)} / \Theta_{v,(i-1) j}\right)
\end{array}\right. \\
& \Theta_{v,(i-1) j}^{\prime}=\Theta_{v,(i-1) j}+\Theta_{o}\left(1+\Theta_{v,(i-1) j} / \Theta_{r, i(j-1)}\right) \\
& \Theta_{c,(i-1)(j-1)}=\Theta_{v,(i-1) j}+\Theta_{r, i(j-1)}\left(1+\Theta_{v,(i-1) j} / \Theta_{o}\right)
\end{aligned}
$$

Multiple transformations of a thermal resistance grid network give rise to lengthy and unwieldy expressions. Therefore, a simple algorithm is developed in MATLAB to obtain the final equivalent thermal resistance of the complicated network (Fig. 5(c)) with any values.

\section{3) Parametric Analysis}

Based on the proposed thermal resistance model for outerzone vias, the dependence of the ultimate thermal resistance of PCB vias on multiple design variables and parameter is plotted in Fig. 8. If the maximum outer via layer number equals 0 , then it means that there are only inner-zone vias. It is seen from Fig. 8 that the thermal resistance decreases with the increase of the outer via layer number. However, the thermal resistance reduction becomes insignificant when the outer via layer number exceeds a certain range, e.g., [2, 4]. It is also observed that the thermal resistance is always 
inversely proportional to the via-to-via spacing $s$; thus, $s$ should be designed possibly small. According to Fig. 8(b), one can conclude that the filler material and via diameter affect the thermal resistance as well. In the case of air filling, the optimal diameter is $0.25 \mathrm{~mm}$. In the case of solder as filler material, the via diameter should be designed larger to decrease the thermal resistance.

\section{Thermal Modeling AND SiZING OF PCB PADS}

For the natural convection in the air, the flow remains laminar when the temperature difference involved is less than $100{ }^{\circ} \mathrm{C}$ and the characteristic length of the body is less than $0.5 \mathrm{~m}$ [38], which is almost always the case in electronic systems. Therefore, the airflow in the following analysis is assumed to be laminar. The natural convection heat transfer coefficient for laminar flow of air at atmospheric pressure, $h_{\text {conv }}$, and the radiation heat transfer coefficient $h_{\text {radi }}$ are [38]

$$
\left\{\begin{aligned}
h_{\text {conv }}= & \lambda\left[\left(T_{x}-T_{a}\right) / L_{c}\right]^{0.25} \\
h_{\text {radi }}= & \varepsilon \sigma\left[\left(T_{x}+273\right)^{2}+\left(T_{a}+273\right)^{2}\right] \\
& \times\left[\left(T_{x}+273\right)+\left(T_{a}+273\right)\right] \\
h= & h_{\text {conv }}+h_{\text {radi }}
\end{aligned}\right.
$$

where $T_{x}$ is the PCB surface temperature, $T_{a}$ is the ambient temperature, and $h$ is the total heat transfer coefficient. The PCB mask is an epoxy-based lacquer, which is an organic material and has a high emissivity of about 0.9 [39].

\section{A. Model Simplification}

Fig. 9(a) shows the vertical cut plane of a multilayer PCB with a chip soldered. As can be seen, multiple vias are normally used to provide an efficient thermal propagation path from the chip to the PCB. Then the heat spreads radially inside the PCB which is further vertically cooled by convection. For the heat transferred inside the PCB, it is obvious that the source originates from the center area.

In addition to the heat source, there are two heat transfer zones, i.e., the middle zone (copper zone) within $\left[r_{b}, r_{s}\right]$ and the outer zone (FR4 zone) within $\left[r_{s}, r_{e}\right]$. For the radial heat conduction, the equivalent thermal conductivities in the two zones can be calculated by [25]

$$
\left\{\begin{array}{l}
k_{1}=k_{C u} N_{C u} t_{C u} / t+k_{F R 4}\left(1-N_{C u} t_{C u} / t\right) \\
k_{2}=k_{F R 4}
\end{array}\right.
$$

If the convective resistance is much larger than the conductive resistance, then the temperature drop over the thickness of a pad is negligible [40]. Thus, the pad can be considered thin, and heat conduction occurs in the radial direction. This assumption holds true when the Biot number $B i$ is small, i.e., [41]

$$
B i=\frac{h t}{k}<0.1
$$

Substituting (11) into (12) yields

$$
N_{C u} t_{C u}>\frac{t\left(10 h t-k_{F R 4}\right)}{k_{C u}-k_{F R 4}}
$$

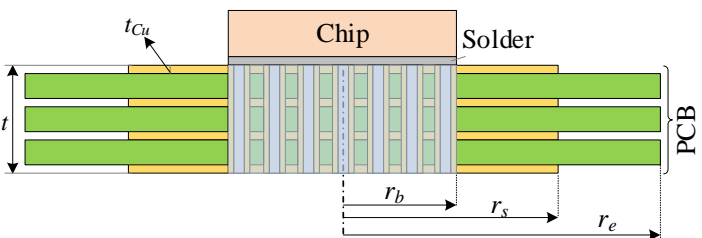

(a)

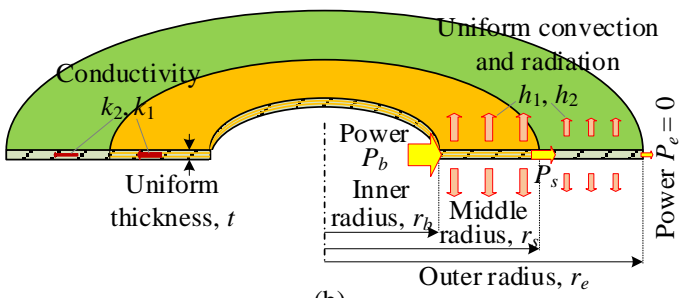

(b)

Fig. 9. Simplified PCB model. (a) Vertical cut plane of a multilayer PCB; (b) Heat transfer in a circular PCB: heat conduction in the radial direction, convection and radiation in the axial direction.

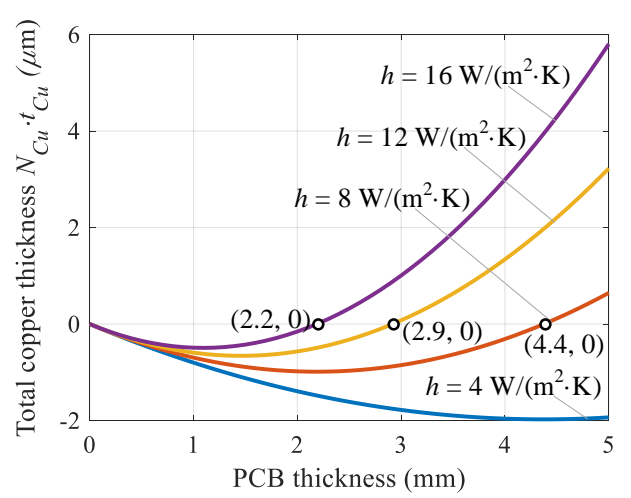

Fig. 10. Lower boundaries of $N_{C u} t_{C u}$ at different PCB thicknesses and heat transfer coefficients in order to satisfy $B i<0.1$.

Based on (13), the lower boundary of $N_{C u} t_{C u}$ with respect to the PCB thickness is depicted at different heat transfer coefficients. With the natural convection, the heat transfer coefficient is normally smaller than $16 \mathrm{~W} /\left(\mathrm{m}^{2} \mathrm{~K}\right)$ [42].

When the PCB is composed of FR4 only (i.e., $N_{C u} t_{C u}=0$ ), its in-plane thermal conductivity reaches the minimum $k_{F R A}$. In order to satisfy $B i<0.1$, the maximum PCB thickness is $2.2 \mathrm{~mm}$ when $h=16 \mathrm{~W} /\left(\mathrm{m}^{2} \mathrm{~K}\right)$. As the decrease of $h$, the allowed maximum PCB thickness increases.

In most cases, there is at least one-layer 0.5-oz copper in a PCB, yielding a total copper thickness of $N_{C u} t_{C u}=17.5 \mu \mathrm{m}$. As can be seen from Fig. 10, the lower boundary of $N_{C u} t_{C u}$ is far below $17.5 \mu \mathrm{m}$ even when the PCB thickness reaches 5 $\mathrm{mm}$. Hence, PCBs can be considered thin, and the temperature drop over their thicknesses can be neglected.

Actual semiconductor chips and PCBs are typically rectangular. Due to the phenomena of radial heat conduction and vertical heat convection in the PCB thermal system shown in Fig. 9(a), it is much easier to analyze the thermal resistance in the cylindrical coordinates. Hence, the rectangular heat source and PCB pad are transformed to axisymmetric circular ones based on ensuring that the total area remains the same, as shown in Fig. 9(b). An axisymmetric heat source (package) is located at the inner radius, and the outer edge is assumed to be isothermal. 


\section{B. Heat Transfer in a Circular PCB}

The general three-dimensional heat-conduction equation in cylindrical coordinates is [43]

$$
\frac{\partial^{2} T}{\partial r^{2}}+\frac{1}{r} \frac{\partial T}{\partial r}+\frac{1}{r^{2}} \frac{\partial^{2} T}{\partial \theta^{2}}+\frac{\partial^{2} T}{\partial z^{2}}+\frac{\dot{P}}{k}=\frac{k}{\rho c} \frac{\partial T}{\partial \tau}
$$

where $r, \theta$, and $z$ denote the radial, azimuthal, and vertical coordinates, respectively, $T$ represents the temperature, $\tau$ denotes time, $\dot{P}$ denotes the power generated per unit volume, $k$ represent the thermal conductivity of a material, $\rho$ is the density, and $c$ is the specific heat.

As discussed in Section III-A, PCB pads can be regarded thin due to the negligible temperature drop over the vertical direction. Assume that the thermal pad is of central symmetry, and thus, the heat transfer in the azimuthal direction can be neglected as well. When the steady state of the thermal system is reached, the temperature does not change with time $\tau$, and thus, (14) can be simplified as

$$
\frac{\mathrm{d}^{2} T}{\mathrm{~d} r^{2}}+\frac{1}{r} \frac{\mathrm{d} T}{\mathrm{~d} r}+\frac{\dot{P}}{k}=0
$$

The PCB is cooled by means of natural convection and radiation. Based on Newton's Law, we have

$$
P=-h A_{z}\left(T-T_{a}\right)
$$

where the temperature-dependent parameter $h$ represents the sum of convective and radiative heat transfer coefficients, and $A_{z}$ denotes the PCB cooling area.

Substituting (16) into (15) yields

$$
\frac{\mathrm{d}^{2} T}{\mathrm{~d} r^{2}}+\frac{1}{r} \frac{\mathrm{d} T}{\mathrm{~d} r}-\frac{h}{k t}\left(T-T_{a}\right)=0
$$

where $t$ denotes the PCB thickness.

According to Fourier's law, the transferred power can be expressed by

$$
P=-k A_{r} \frac{\mathrm{d} T}{\mathrm{~d} r}=-2 k \pi r t \frac{\mathrm{d} T}{\mathrm{~d} r}
$$

where $A_{r}$ is the PCB area in the radial direction when the radius equals $r$.

The general solutions of (17) and (18) can be obtained as

$$
\left\{\begin{array}{l}
\Delta T=a I_{0}(z)+b K_{0}(z) \\
P=-2 \pi k t z\left[a I_{1}(z)+b K_{1}(z)\right]
\end{array}\right.
$$

where $\Delta T=T-T_{a}, z=r \sqrt{h /(k t)}, I_{0}$ is the modified Bessel function of the first kind and order $0, I_{1}$ is the modified Bessel function of the first kind and order $1, K_{0}$ is the modified Bessel function of the second kind and order $0, K_{1}$ is the modified Bessel function of the second kind and order 1 , and $a$ and $b$ are arbitrary constants. Eliminating $a$ and $b$, and applying the two-port theory yield

$$
\left[\begin{array}{c}
\Delta T_{i} \\
P_{i}
\end{array}\right]=\mathbf{T}_{i j}\left[\begin{array}{c}
\Delta T_{j} \\
P_{j}
\end{array}\right]=\left[\begin{array}{cc}
A_{i j} & B_{i j} \\
C_{i j} & D_{i j}
\end{array}\right]\left[\begin{array}{c}
\Delta T_{j} \\
P_{j}
\end{array}\right]
$$

where the subscript $i$ and $j$ represent the sending and receiving ports at any locations, $\mathbf{T}_{i j}$ is the transmission matrix, $z_{i}=r_{i} \sqrt{h /(k t)}, A_{i j}=z_{j}\left[I_{1}\left(z_{j}\right) K_{0}\left(z_{i}\right)+I_{0}\left(z_{i}\right) K_{1}\left(z_{j}\right)\right]$, $z_{j}=r_{j} \sqrt{h /(k t)}$,

$B_{i j}=\left[I_{0}\left(z_{j}\right) K_{0}\left(z_{i}\right)-I_{0}\left(z_{i}\right) K_{0}\left(z_{j}\right)\right] /(2 \pi k t)$,

$C_{i j}=2 \pi k t z_{i} z_{j}\left[I_{1}\left(z_{j}\right) K_{1}\left(z_{i}\right)-I_{1}\left(z_{i}\right) K_{1}\left(z_{j}\right)\right]$, and

$D_{i j}=z_{i}\left[I_{0}\left(z_{j}\right) K_{1}\left(z_{i}\right)+I_{1}\left(z_{i}\right) K_{0}\left(z_{j}\right)\right]$.

The heat transfer from $r_{s}$ to $r_{e}$ (including radial conduction and axial convection and radiation) can be illustrated with a two-port system, i.e., the temperature potential $\Delta T_{s}$ and heat flow $P_{s}$ can be obtained as (20). Assume that the outer edge of $r=r_{e}$ is adiabatic in the horizontal direction, i.e., $P_{e}=0$, then the thermal resistance from $r_{s}$ to the ambient, $\Theta_{s a}$, can be derived as

$$
\begin{gathered}
{\left[\begin{array}{c}
\Delta T_{s} \\
P_{s}
\end{array}\right]=\mathbf{T}_{s e}\left[\begin{array}{c}
\Delta T_{e} \\
0
\end{array}\right]=\left[\begin{array}{ll}
A_{s e} & B_{s e} \\
C_{s e} & D_{s e}
\end{array}\right]\left[\begin{array}{c}
\Delta T_{e} \\
0
\end{array}\right]} \\
\Theta_{s a}=\frac{\Delta T_{s}}{P_{s}}=\frac{A_{s e}}{C_{s e}}
\end{gathered}
$$

As for the two-port system from $r_{b}$ to $r_{s}$, we have

$$
\begin{aligned}
{\left[\begin{array}{c}
\Delta T_{b} \\
P_{b}
\end{array}\right] } & =\mathbf{T}_{b s}\left[\begin{array}{c}
\Delta T_{s} \\
P_{s}
\end{array}\right]=\left[\begin{array}{ll}
A_{b s} & B_{b s} \\
C_{b s} & D_{b s}
\end{array}\right]\left[\begin{array}{c}
\Delta T_{s} \\
P_{s}
\end{array}\right]=\mathbf{T}_{b s} \mathbf{T}_{s e}\left[\begin{array}{c}
\Delta T_{e} \\
0
\end{array}\right] \\
& =\left[\begin{array}{cc}
A_{b s} A_{s e}+B_{b s} C_{s e} & A_{b s} B_{s e}+B_{b s} D_{s e} \\
C_{b s} A_{s e}+D_{b s} C_{s e} & C_{b s} B_{s e}+D_{b s} D_{s e}
\end{array}\right]\left[\begin{array}{c}
\Delta T_{e} \\
0
\end{array}\right]
\end{aligned}
$$

Then the thermal resistance from $r_{b}$ to the ambient, and the temperature at $r_{b}$ can be obtained

$$
\begin{gathered}
\Theta_{b a}=\frac{\Delta T_{b}}{P_{b}}=\frac{A_{b s} A_{s e}+B_{b s} C_{s e}}{C_{b s} A_{s e}+D_{b s} C_{s e}} \\
T_{b}=T_{a}+P_{b} \Theta_{b a}
\end{gathered}
$$

where $P_{b}$ represents the power injected to the board.

Manipulating (21) and (23) yields the equivalent thermal resistance from $r_{s}$ to the ambient and the thermal resistance from $r_{e}$ to the ambient when an axisymmetric heat source is located at $r_{b}$

$$
\begin{aligned}
& \psi_{s a}=\frac{\Delta T_{s}}{P_{b}}=\frac{A_{s e}}{C_{b s} A_{s e}+D_{b s} C_{s e}} \Rightarrow T_{s}=T_{a}+P_{b} \psi_{s a} \\
& \psi_{e a}=\frac{\Delta T_{e}}{P_{b}}=\frac{1}{C_{b s} A_{s e}+D_{b s} C_{s e}} \Rightarrow T_{e}=T_{a}+P_{b} \psi_{e a}
\end{aligned}
$$

It should be noted that $\psi_{s a}$ and $\psi_{e a}$ are defined similarly to the thermal metric $\psi_{J T}$ adopted by the industry (JEDEC Standard: JESD51-2 [44]). They are not true thermal resistances but can be used to calculate the temperatures at $r_{s}$ and $r_{e}$.

The analysis above is carried out by assuming the heat source, copper pad and PCB are circular. The equivalent radius of a rectangular pad can be approximated by $r_{x}=\sqrt{a_{x} b_{x} / \pi}$ where $a_{x}$ and $b_{x}$ are the rectangular side lengths, and the subscript ' $x$ ' denotes ' $b$ ', ' $s$ ', and ' $e$ '.

\section{Heat Transfer Boundary}

In order to satisfy the boundary condition that there is no conductive heat flow at $r_{e}$, the thermal resistance $\Theta_{s a}(22)$ is investigated with respect to different parameters, i.e., $r_{e}, t$, and $h$, as shown in Fig. 11(a). When $r_{s}$ is specified, the 


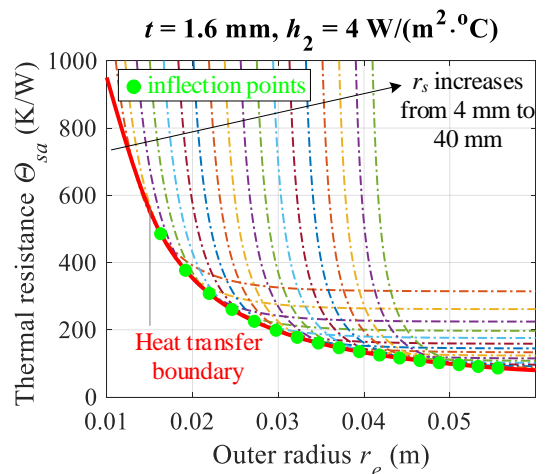

(a)

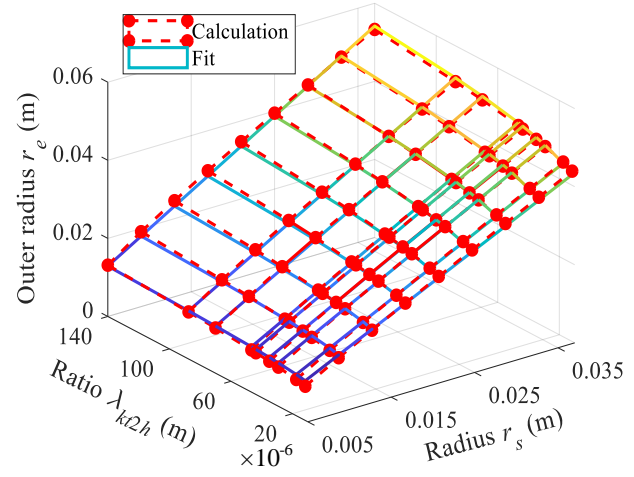

(b)

Fig. 11. (a) Curves of the thermal resistance $\Theta_{s a}$ with respect to $r_{s}$ and $r_{e}$. (b) The heat transfer boundary $r_{e}$ versus the copper radius $r_{s}$ and the ratio $\lambda_{k t 2 h}$.

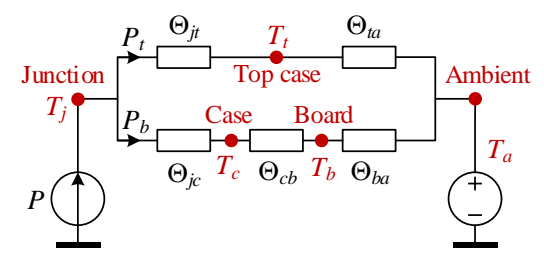

Fig. 12. Equivalent thermal resistance diagram for a DPAK package mounted on a PCB. The thermal resistance of the thin solder between the package and the PCB is small and therefore is neglected [45].

thermal resistance $\Theta_{s a}$ decreases with respect to the increase of $r_{e}$; however, the decrease of $\Theta_{s a}$ becomes insignificant when $r_{e}$ exceeds the inflection point $r_{e c}$, which means that the heat flow beyond $r_{e c}$ can be negligible and the inflection points can be chosen as the heat transfer boundary. It should be noted that $r_{e c}$ depends on both the copper radius $r_{s}$ and the ratio of $k \cdot t$ to $h_{2}$, i.e., $\lambda_{k t 2 h}=k t / h_{2}$. It is quite difficult to directly obtain the analytical expression of $r_{e c}$. Therefore, curve fitting is carried out, as shown in Fig. 11(b). It is found that the outer radius $r_{e}$ can be determined by

$$
r_{e}=3 \lambda_{k t 2 h}^{0.095}\left(r_{s}+0.005\right)
$$

\section{Algorithm for Copper Pad Sizing}

When an SMD is mounted on a PCB, the heat generated inside the device will dissipate in two parallel pathways: one is from the junction, then to the top case, and finally to the ambient; the other is from the junction to the bottom case, then to the board, and finally to the ambient. The heat flow rates in the two paths are termed as $P_{t}$ and $P_{b}$, respectively.
Obviously, we have $P=P_{t}+P_{b}$. Fig. 12 shows the equivalent thermal resistance diagram for a DPAK package mounted on a PCB.

If all the thermal resistances are known, then the top-case and junction temperatures can be predicted by

$$
T_{t}=\frac{P\left(\Theta_{j c}+\Theta_{c b}+\Theta_{b a}\right)}{\Theta_{j t}+\Theta_{t a}+\Theta_{j c}+\Theta_{c b}+\Theta_{b a}} \Theta_{t a}+T_{a}=P_{b} \psi_{t a}+T_{a}
$$

where the equivalent top-case-ambient thermal resistance

$$
\begin{gathered}
\psi_{t a}=\frac{\left(\Theta_{j c}+\Theta_{c b}+\Theta_{b a}\right) \Theta_{t a}}{\Theta_{j t}+\Theta_{t a}} \\
T_{j}=\frac{P\left(\Theta_{j t}+\Theta_{t a}\right)\left(\Theta_{j c}+\Theta_{c b}+\Theta_{b a}\right)}{\Theta_{j t}+\Theta_{t a}+\Theta_{j c}+\Theta_{c b}+\Theta_{b a}}+T_{a}
\end{gathered}
$$

If the top-case temperature $T_{t}$ and other thermal resistances are determined, then the board-ambient thermal resistance $\Theta_{b a}$ can be expressed as

$$
\Theta_{b a}=\frac{P \Theta_{t a}\left(\Theta_{j t}+\Theta_{t a}\right)}{P \Theta_{t a}+T_{a}-T_{t}}-\Theta_{j c}-\Theta_{c b}-\Theta_{j t}-\Theta_{t a}
$$

For the heat transfers from the junction to the top case, from the junction to the case, and from the case to the board, there is only heat conduction, and therefore the corresponding thermal resistances $\Theta_{j t}, \Theta_{j c}$, and $\Theta_{c b}$ are constant if neglecting the relatively small material property variation over temperature. However, the heat transfers from the top case to the ambient and from the board to the ambient involve convection and radiation. Hence, the thermal resistances $\Theta_{t a}$ and $\Theta_{b a}$ are temperature dependent.

As seen from (25)-(27), and (29), a temperature $T_{x}$ can be obtained by

$$
T_{x}=P_{b} \Theta_{x}+T_{a}
$$

where $T_{x}$ denotes the temperature $T_{b}, T_{s}, T_{e}$ or $T_{t}$, and $\Theta_{x}$ represents the thermal resistance $\Theta_{b a}, \psi_{\underline{s a}}, \psi_{e a}$ or $\psi_{e a}$. It is concluded from (10) that $\Theta_{x}$ is a monotonically decreasing function of $T_{x}$ :

$$
\Theta_{x}=f_{x}\left(T_{x}\right)
$$

The higher the temperature $T_{x}$, the lower the thermal resistance $\Theta_{x}$. Substituting (34) into (33) yields

$$
T_{x}=P_{b} f_{x}\left(T_{x}\right)+T_{a}=\varphi_{x}\left(T_{x}\right)
$$

Due to the fact that both $P_{b}$ and $\Theta_{x}$ are positive, $\varphi_{x}\left(T_{x}\right)=$ $P_{b} \Theta_{x}+T_{a}$ is always larger than $T_{a}$. The thermal resistance $\Theta_{x}$ is a monotonically decreasing function of $T_{x}$, and therefore $\varphi_{x}\left(T_{x}\right)$ is also monotonically decreasing with respect to $T_{x}$. The full expression of (35) can be obtained by substituting (10), (24), (26), (27) and (29) into (33). However, the final transcendental equations do not have analytical solutions. Therefore, the fixed-point iteration method [46] is used to obtain the solution of (35). The iterative scheme with the recursive relation is

$$
T_{x, c+1}=\varphi_{x}\left(T_{x, c}\right)
$$

where the subscript " $c$ " represents the iteration order. Fig. 13. shows the fixed-point iterative trajectories of $T_{x}=\varphi_{x}\left(T_{x}\right)$ at different initial points. The solution, i.e., temperature 


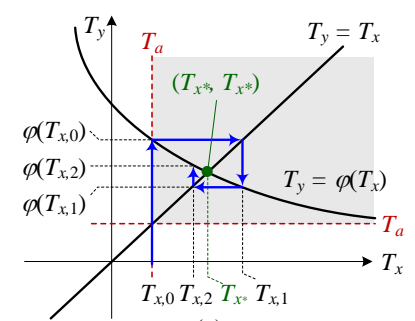

(a)

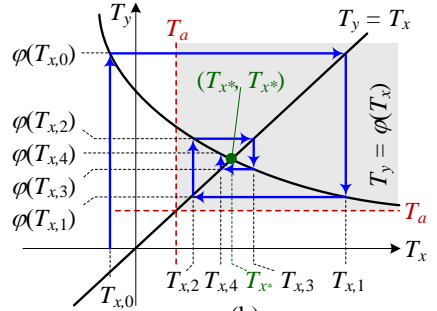

(b)

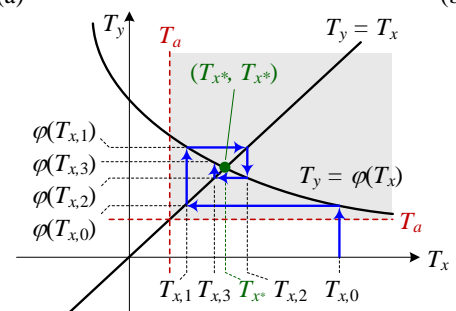

(c)

Fig. 13. Fixed-point iterative schemes at different initial points. (a) The initial point equals the ambient temperature, i.e., $T_{x, 0}=T_{a}$; (b) the initial point is lower than the ambient temperature, i.e., $T_{x, 0}<T_{a}$; (c) The initial point is higher than the ambient temperature, i.e., $T_{x, 0}>T_{a}$.

point $\left(T_{x^{*}}, T_{x^{*}}\right)$ locates in the shaded region, i.e., $T_{x}>T_{a}$ and $T_{y}>T_{a}$. Therefore, the initial iteration value of $T_{x, 0} \geq T_{a}$ enables fewer iteration times, as illustrated in Fig. 13. However, it is noted that when the initial value $T_{x, 0}$ is smaller than $T_{a}$, it takes only one iteration before the iterative value enters the shaded region. This is because that $\varphi_{x}\left(T_{x}\right)=P_{b} \Theta_{x}$ $+T_{a}$ is always larger than $T_{a}$. Hence, the iteration speed does not vary much with respect to the initial value $T_{x, 0}$.

A fixed-point iteration based algorithm taking into account all the five thermal resistances shown in Fig. 12 is developed to design the copper pad size, as shown in Fig. 14.

Before the design, the system parameters, e.g., the ambient temperature $T_{a}$, total Power loss $P$, PCB thickness $t$, copper thickness $t_{C u}$, number of copper layers $N_{C u}$, package radius $r_{b}$, junction-top-case thermal resistance $\Theta_{j t}$, junction-case thermal resistance $\Theta_{j c}$, case-board thermal resistance $\Theta_{c b}$, allowed maximum junction temperature $T_{\text {jmax }}$, should be determined. Then, a small initial value is given to the copper pad radius $r_{s}$ before the four initial given temperatures $T_{t, g}$, $T_{e, g}, T_{s, g}$, and $T_{b, g}$, are initialized as $T_{t, 0}, T_{e, 0}, T_{s, 0}$, and $T_{b, 0}$, respectively. Then the heat transfer coefficients $h_{1}$ and $h_{2}$ can be calculated based on (10), and the thermal resistances $\Theta_{t a}$, $\Theta_{b a}, \psi_{s a}$, and $\psi_{e a}$ can be obtained accordingly. After that, the calculated temperatures $T_{t, c}, T_{e, c}, T_{s, c}$ and $T_{b, c}$ are compared with the given temperatures $T_{t, g}, T_{e, g}, T_{s, g}$, and $T_{b, g}$; also the errors can be obtained, i.e., $\varepsilon_{t}=T_{t, c}-T_{t, g}, \varepsilon_{e}=T_{e, c}-T_{e, g}, \varepsilon_{s}=$ $T_{s, c}-T_{s, g}$, and $\varepsilon_{b}=T_{b, c}-T_{b, g}$. If the absolute error $\varepsilon_{x}$ is greater than the preset limit $\varepsilon_{l m t}$, then the given temperature $T_{x, g}$ will be updated by the calculated temperature $T_{x, c}$ and the subscript $x$ represents ' $t$ ', ' $e$ ', ' $s$ ', or ' $b$ '. If all four temperatures errors are smaller than $\varepsilon_{l m t}$, then the algorithm proceeds to calculate the junction temperature $T_{j}$ according to (31). If the calculated $T_{j}$ is higher than the allowed maximum junction temperature, then the copper pad radius $r_{e}$ will be increased. Otherwise, it implies that current copper pad radius $r_{e}$ is large enough for cooling. In this way, we can find the minimum $r_{e}$ which helps to achieve the maximum power density while meeting the thermal specifications.

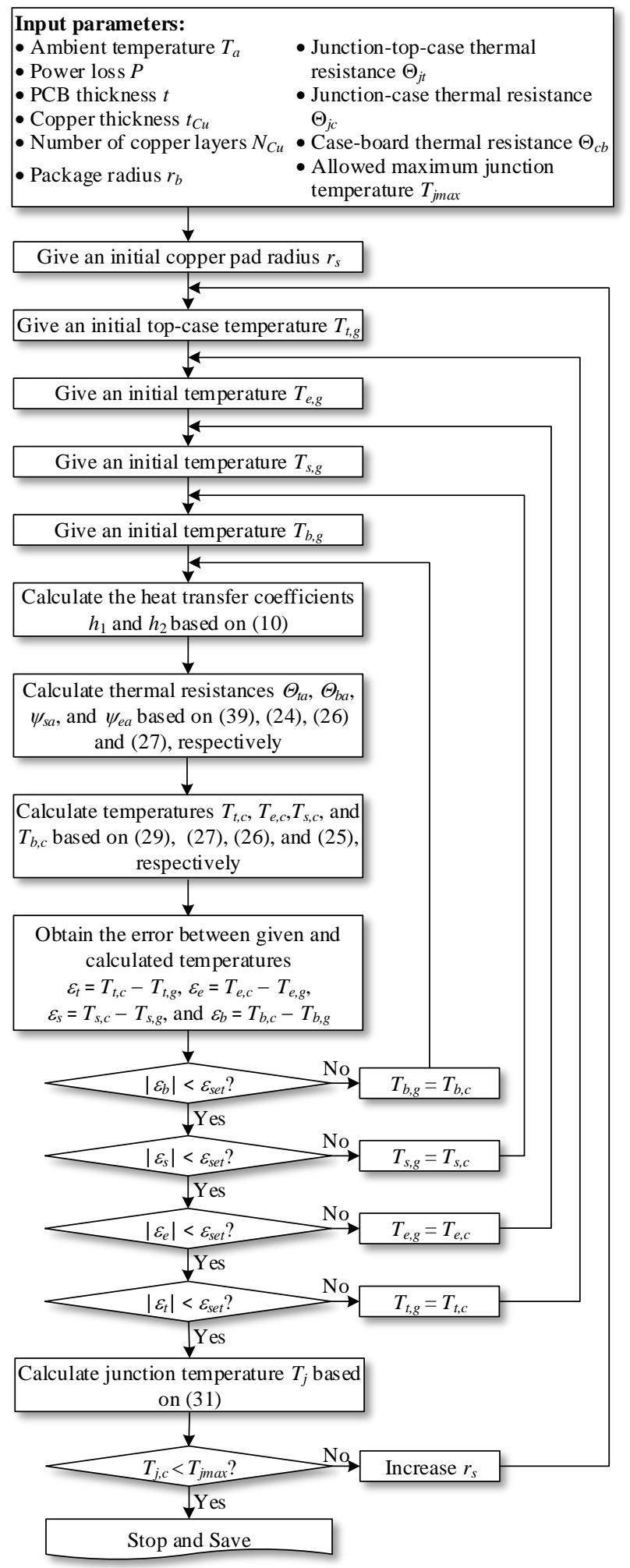

Fig. 14. Flowchart of sizing a PCB thermal pad to satisfy the requirement of below the specified maximum junction temperature.

Fig. 15 shows the elapsed time to run the algorithm shown in Fig. 14 with MATLAB 2018b. Although a small temperature error limit $0.01{ }^{\circ} \mathrm{C}$ is set, the average elapsed times are as short as approximately $30 \mathrm{~ms}$. Also, it is seen that the average times do not vary significantly for the three 


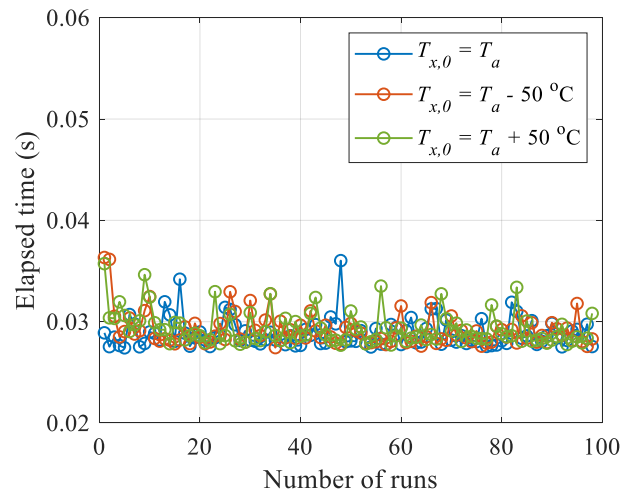

Fig. 15. Elapsed time to run the algorithm in Fig. 14 with MATLAB R2018b. (a)

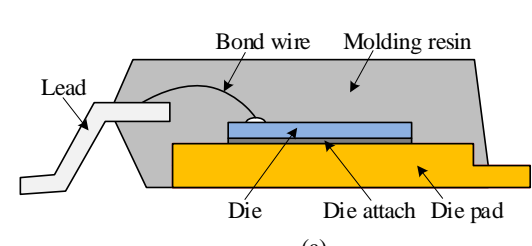

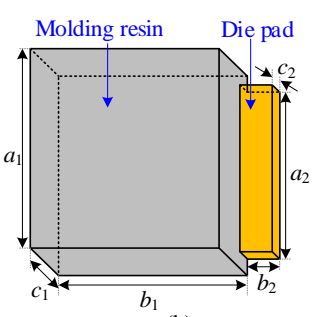

(b)
Fig. 16. (a) DPAK package structure; (b) Simplified package outline dimensions of diode VS-6EWL06FN-M3 [49].

selected initial iteration values, which agrees well with previous analysis. Nevertheless, the iteration can be further accelerated by using advanced methods, e.g., the Aitken's delta-squared process [47] and the Steffensen's method [48].

\section{E. Thermal Modeling of DPAK Package}

As mentioned before, when an SMD is mounted on a PCB, the equivalent thermal resistance diagram is shown in Fig. 12. Apart from the board to ambient thermal resistance $\Theta_{b a}$, the realization of the proposed algorithm shown in Fig. 14 also requires the knowledge of the other four thermal resistances $\Theta_{c b}, \Theta_{j t}, \Theta_{t a}$, and $\Theta_{j c}$. The case-board thermal resistance $\Theta_{c b}$ can be obtained from the analysis in Section II. For the other three thermal resistances $\Theta_{j t}, \Theta_{t a}$, and $\Theta_{j c}$, however, they are package dependent and are usually not available in datasheets. Therefore, the detailed structure model and simplified package outline dimensions of DPAK package are derived, as shown in Fig. 16.

An analytical model of the thermal resistance $\Theta_{t a}$ is firstly developed. Its side and top surfaces are cooled by natural convection and radiation. Thus, the heat transfer from the surfaces of the diode to the ambient involves the heat conduction, convection and radiation, and the heat transfer coefficient depends on both the ambient temperature and the temperature difference between the surfaces and the ambient.

Assume that the package is placed horizontally, and its surfaces share the same temperature $T_{t}$. For the horizontal top surfaces of the molding resin and die pad (see Fig. 16(b)), their areas are $A_{h o r 1}=a_{1} b_{1}$ and $A_{h o r 2}=a_{2} b_{2}$, respectively. Based on [38], the characteristic lengths of the two rectangular surfaces under natural convection can be calculated as $L_{c, h o r 1}=a_{1} b_{1} /\left[\left(a_{1}+b_{1}\right) / 2\right]$ and $L_{c, h o r 2}=a_{2} b_{2} /\left[\left(a_{2}+b_{2}\right) / 2\right]$, respectively. Then, we can obtain the convective heat transfer coefficients of the two top surfaces [38], i.e.,

$$
\left\{\begin{aligned}
h_{\text {hor }, \text { conv } 1} & =\lambda_{\text {hor }}\left[\left(T_{t}-T_{a}\right) / L_{c, h o r 1}\right]^{0.25} \\
& =\lambda_{\text {hor }}\left[\left(a_{1}+b_{1}\right)\left(T_{t}-T_{a}\right) /\left(2 a_{1} b_{1}\right)\right]^{0.25} \\
h_{\text {hor }, \text { conv } 2} & =\lambda_{\text {hor }}\left[\left(T_{t}-T_{a}\right) / L_{c, h o r 2}\right]^{0.25} \\
& =\lambda_{\text {hor }}\left[\left(a_{2}+b_{2}\right)\left(T_{t}-T_{a}\right) /\left(2 a_{2} b_{2}\right)\right]^{0.25}
\end{aligned}\right.
$$

where $\lambda_{\text {hor }}=1.32$ is a constant for horizontal plates [38].

Similarly, the convective heat transfer coefficients of the vertical surfaces of the molding resin and die pad with areas of $A_{v e r 1}=2 c_{1}\left(a_{1}+b_{1}\right)-a_{2} c_{2}$ and $A_{v e r 2}=c_{2}\left(a_{2}+2 b_{2}\right)$ can be obtained as

$$
\left\{\begin{aligned}
h_{\text {ver }, \text { con } 1} & =\lambda_{\text {ver }}\left[\left(T_{t}-T_{a}\right) / L_{c, \text { ver } 1}\right]^{0.25} \\
& =\lambda_{\text {ver }}\left[\left(T_{t}-T_{a}\right) / c_{1}\right]^{0.25} \\
h_{\text {ver,conv } 2} & =\lambda_{\text {ver }}\left[\left(T_{t}-T_{a}\right) / L_{c, v e r 2}\right]^{0.25} \\
& =\lambda_{\text {ver }}\left[\left(T_{t}-T_{a}\right) / c_{2}\right]^{0.25}
\end{aligned}\right.
$$

where $\lambda_{v e r}=0.59$ is a constant for vertical plates [38].

Considering both the convection and radiation, the thermal resistance from the package surface to the ambient can be obtained as

$$
\begin{aligned}
\Theta_{t a} & =\frac{1}{A_{h o r 1}\left(h_{h o r, c o n v 1}+h_{\text {radi } 1}\right)+A_{h o r 2}\left(h_{h o r, c o n v 2}+h_{\text {radi } 2}\right)+A_{\text {ver } 1}\left(h_{\text {ver }, \text { conv } 1}+h_{\text {radi } 1}\right)+A_{\text {ver } 2}\left(h_{\text {ver, }, \text { conv } 2}+h_{\text {radi } 2}\right)} \\
& =\frac{1}{\left[\begin{array}{l}
2 c_{1}\left(a_{1}+b_{1}\right)\left(\lambda_{\text {ver }}\left[\left(T_{t}-T_{a}\right) / c_{1}\right]^{0.25}+h_{\text {radi } 1}\right)+c_{2}\left(a_{2}+2 b_{2}\right)\left(\lambda_{\text {ver }}\left[\left(T_{t}-T_{a}\right) / c_{2}\right]^{0.25}+h_{\text {radi } 2}\right) \\
+a_{1} b_{1}\left(\lambda_{\text {hor }}\left[\left(a_{1}+b_{1}\right)\left(T_{t}-T_{a}\right) /\left(2 a_{1} b_{1}\right)\right]^{0.25}+h_{\text {radi } 1}\right)+a_{2} b_{2}\left(\lambda_{\text {hor }}\left[\left(a_{2}+b_{2}\right)\left(T_{t}-T_{a}\right) /\left(2 a_{2} b_{2}\right)\right]^{0.25}+h_{\text {radi } 2}\right)
\end{array}\right)}
\end{aligned}
$$

where the radiative heat transfer coefficients $h_{\text {radi1 }}=\varepsilon_{1} \sigma\left(T_{a}+273+T_{t}+273\right)\left[\left(T_{a}+273\right)^{2}+\left(T_{t}+273\right)^{2}\right]$ and $h_{\text {radi2 }}=\varepsilon_{2} \sigma\left(T_{a}+273+T_{t}+273\right)\left[\left(T_{a}+273\right)^{2}+\left(T_{t}+273\right)^{2}\right]$ are for the molding resin surface and the tab surface, respectively; $\varepsilon_{1}$ and $\varepsilon_{2}$ are the emissivities of the molding resin and tab surfaces, respectively.

As for the other two thermal resistances $\Theta_{j c}$ and $\Theta_{j t}$, their values relate to the conductive heat transfer inside the DPAK package, and therefore CFD simulations with ANSYS Icepak 18.0 are conducted, as discussed in Section IV-A. 


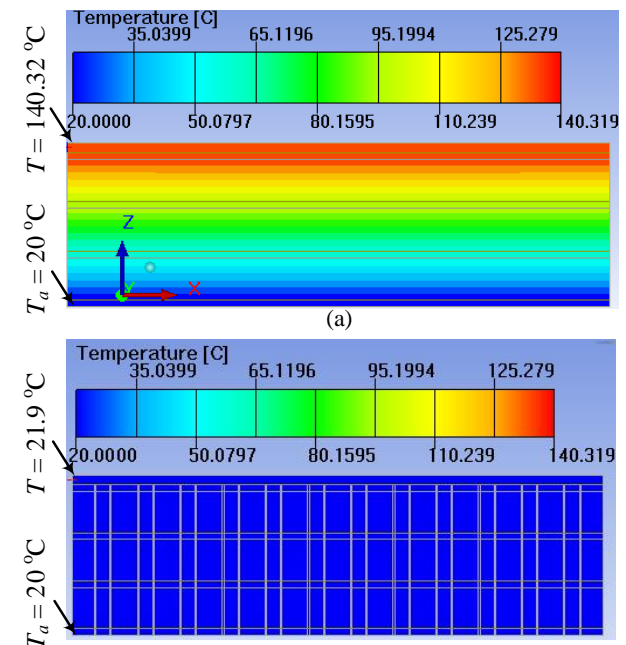

(b)

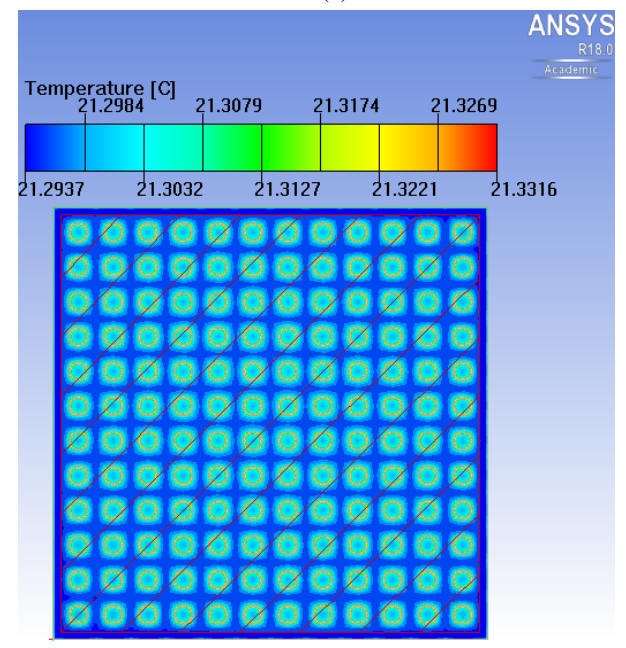

(c)

Fig. 17 CFD simulations of PCBs with the simulation tool ANSYS Icepak $^{\mathrm{TM}}$ 18.0. The top surface of each PCB generates 1-W power loss, whereas the bottom surface is fixed at the ambient temperature $T_{a}=20^{\circ} \mathrm{C}$. PCB parameters in common: 5.6-mm length $\times 5.6-\mathrm{mm}$ width $\times 1.6-\mathrm{mm}$ thickness, 4 copper layers, and $2 \mathrm{oz}$ for each layer. (a) Temperature contour on a vertical cut plane of the PCB without vias; (b) Temperature contour on a vertical cut plane of the PCB with unfilled vias of $0.25-\mathrm{mm}$ diameter; (c) Temperature contour on a horizontal cut plane of the PCB with unfilled vias of $0.25-\mathrm{mm}$ diameter.

\section{CFD SIMULATION AND EXPERIMENTAL VERIFICATIONS OF PROPOSED THERMAL MODELS}

\section{A. CFD Simulations}

ANSYS Icepak provides powerful electronic cooling solutions which utilize the ANSYS Fluent CFD solver for thermal and fluid flow analyses. In order to verify the proposed thermal models of PCBs, CFD simulations are conducted in ANSYS Icepak 18.0 with the pressure-based ANSYS Fluent solver [50], [51].

The CFD simulation results of a PCB via array for the DPAK package are shown in Fig. 17. As can be seen, the thermal resistance of the PCB pad is significantly reduced from $120.3 \mathrm{~K} / \mathrm{W}$ (no via, see Fig. 17(a)) to $1.86 \mathrm{~K} / \mathrm{W}$ (via diameter $\phi=0.25 \mathrm{~mm}$, see Fig. 17(b)).

The calculated and simulated results for different via patterns, diameters and filler materials are shown in Fig. 18.

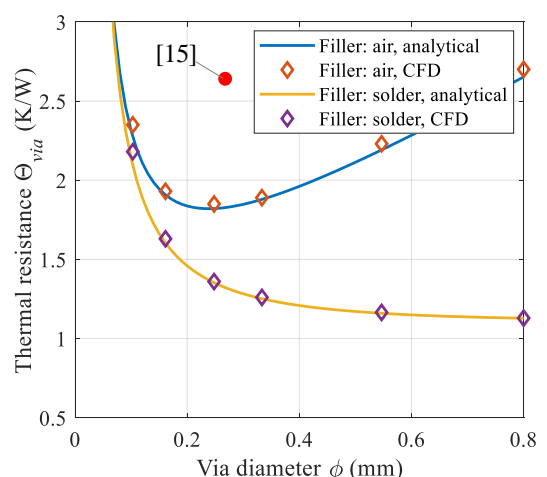

(a)

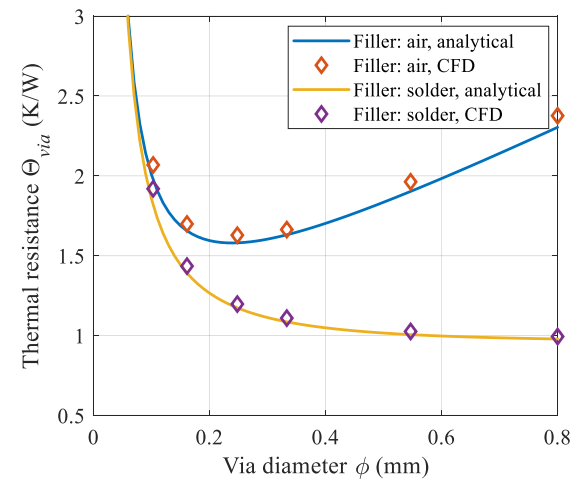

(b)

Fig. 18. Comparison between the calculated and simulated thermal resistance of DPAK (TO252) via array with different parameters: (a) Pattern I and (b) Pattern II.

It is seen that there is a good agreement between calculations and simulations. Also, it indicates that a proper design of the vias (i.e., the pattern, diameter, filler material, etc) enables a remarkable reduction for the thermal resistance. Compared to the reference design provided in [15], the thermal resistance can be reduced up to $62 \%$, i.e., from $2.63 \mathrm{~K} / \mathrm{W}$ (see Fig. 18(a)) based on [15] to $0.98 \mathrm{~K} / \mathrm{W}$ with the proposed optimal design trajectory (Pattern $I I, \phi=0.8 \mathrm{~mm}$, solder filling, see Fig. 18(b)).

As mentioned in Section III-E, a detailed structural model has been built for the DPAK package based on real dimensions. Thermal simulations are then performed in ANSYS Icepak 18.0 to obtain the junction-case and junctiontop-case thermal resistances $\Theta_{j c}$ and $\Theta_{j t}$, as shown in Fig. 19(a) and (b). It is found that the two thermal resistances are $\Theta_{j c}=2.47^{\circ} \mathrm{C} / \mathrm{W}$ and $\Theta_{j c}=44.12^{\circ} \mathrm{C} / \mathrm{W}$, respectively.

To verify the built analytical thermal resistance model of $\Theta_{t a}$, multiple CFD simulations are also conducted in ANSYS Icepak 18.0, as shown in Fig. 19(c) and Fig. 20. It is seen that there is a negligible error (maximum error $=3.2 \%$ ) between the simulations and the analytical results (39).

\section{B. Experimental Verifications}

A curve tracer B1506A from Keysight Technologies is used to measure the $I-V$ characteristics of a batch of VS6EWL06FN-M3 diodes, as shown in Fig. 21(a). It is seen that the voltage drop difference is small. For instance, when the forward current $I_{F}=3 \mathrm{~A}$, the maximum forward voltage difference is $0.944 \mathrm{~V}-0.93 \mathrm{~V}=0.014 \mathrm{~V}$, which represents only $1.5 \%$ of the average forward voltage $0.934 \mathrm{~V}$. 


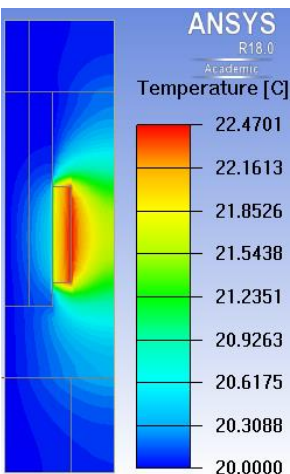

(a)

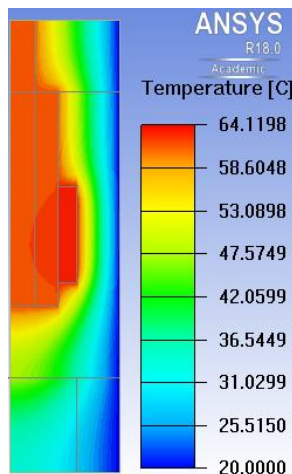

(b)

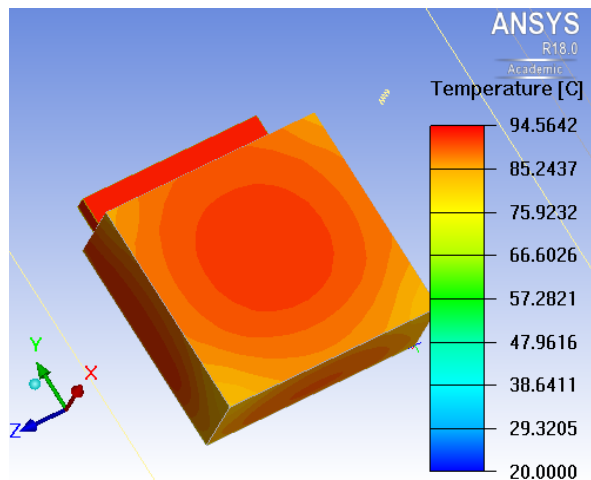

(c)

Fig. 19. CFD simulation results of diode VS-6EWL06FN-M3 in ANSYS Icepak 18.0. (a) Simulation results for the junction-case thermal resistance $\Theta_{j c}$; boundary conditions: $1-\mathrm{W}$ power loss is generated on the top surface of the die, the case temperature is fixed at the ambient temperature $20{ }^{\circ} \mathrm{C}$, and other surfaces of the diode are adiabatic. (b) Simulation results for the junction-top-case thermal resistance $\Theta_{j t}$; boundary conditions: $1-\mathrm{W}$ power loss is generated on the top surface of the die, the top-case temperature is fixed at the ambient temperature $20{ }^{\circ} \mathrm{C}$, and other surfaces of the diode are adiabatic. (c) Simulation results for the top-case-ambient thermal resistance $\Theta_{t a}$; boundary conditions: $0.2-\mathrm{W}$ power loss is injected on the top surface of the die, and the surfaces of the diode are opening to the ambient.

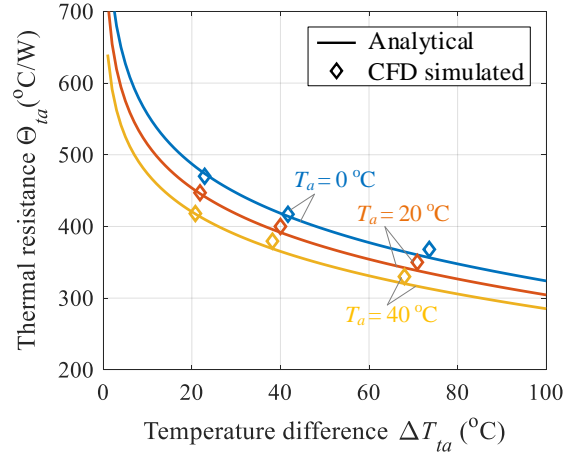

Fig. 20. Comparison between CFD simulations and the analytical model (39) for the top-case-ambient thermal resistance of the DPAK diode VS6EWL06FN-M3.

Nevertheless, the 16 diodes with close $I-V$ characteristics (maximum forward voltage difference $=0.08 \%$ at $I_{F}=3 \mathrm{~A}$ ) are used to build the experimental setups for PCB thermal measurements, as shown in Fig. 21(b) and (c). Nevertheless, the $I-V$ characteristic of a diode varies significantly with the junction temperature. In order to make sure that all the diodes generate the same power loss, each diode is connected to a separate dc power source. Also, a voltage meter and a current meter are used to monitor the consumed power by each diode.

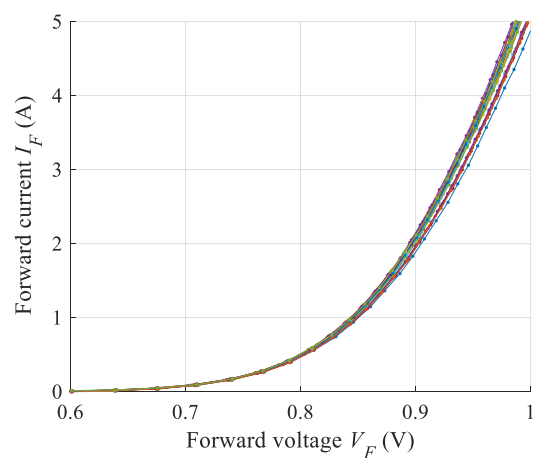

(a)

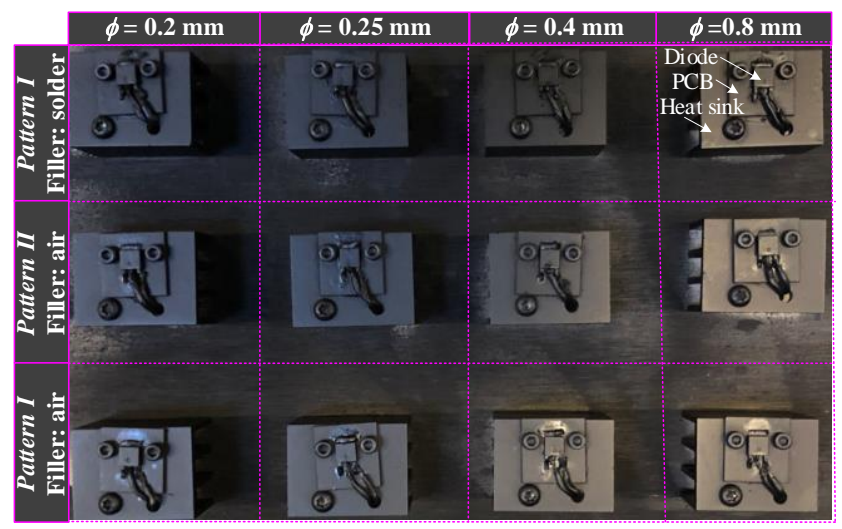

(b)

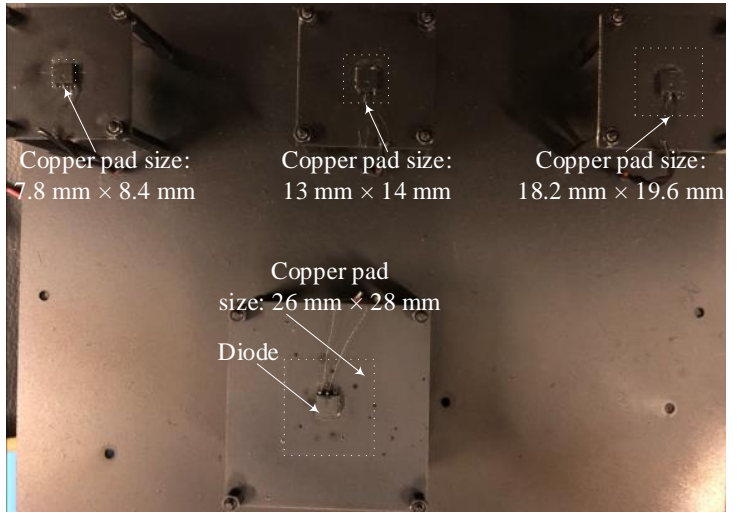

(c)

Fig. 21. Experimental setups. (a) Measured $I_{F}-V_{F}$ curves of $50 \mathrm{VS}$ 6EWL06FN-M3 diodes at $25^{\circ} \mathrm{C}$ by using a curve tracer B1506A from Keysight Technologies. (b) Photo of the experimental setup for PCB vias. Each diode is soldered on a heatsink-cooled PCB with a specified via design. (c) Photo of the built PCB thermal pads with different copper areas.

The vertical structure of a diode mounted on a heatsinkcooled PCB is shown in Fig. 22(a). For the power loss generated inside the diode and dissipated to the ambient, two heat transfer paths exist, i.e., the one through the diode's top case, and the other one through the diode's bottom case, PCB vias, and heatsink. The equivalent thermal resistance diagram is shown in Fig. 22(b). In addition to the thermal resistance of PCB via $\Theta_{v i a}$, other thermal resistances (e.g., $\Theta_{j c}$, $\Theta_{j t}, \Theta_{h a}, \Theta_{t a}, \Theta_{\text {solder }}$, and $\left.\Theta_{T I M}\right)$ also affect the cooling of the diode. In contrast to the junction temperature of a diode, the top-case temperature $T_{t}$ can be more easily measured with an infrared camera, and also $T_{t}$ can be calculated with (40) if all thermal resistances are known. 


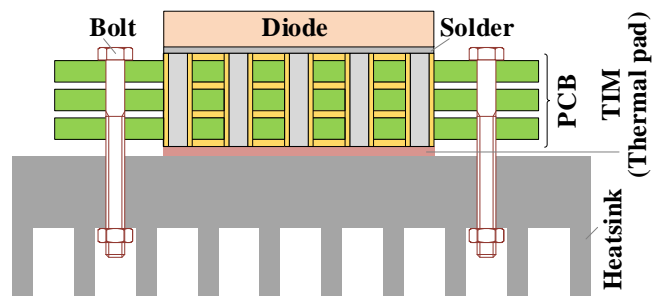

(a)

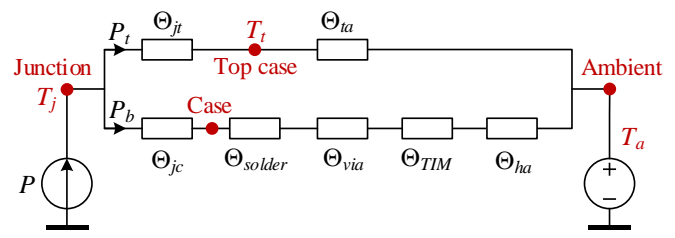

(b)

Fig. 22. (a) Vertical structure and (b) equivalent thermal resistance diagram when a DPAK diode VS-6EWL06FN-M3 is mounted on a heatsink-cooled PCB. $\Theta_{j c}, \Theta_{j t}, \Theta_{h a}$, and $\Theta_{t a}$ represent the junction-case, junction-top-case, heatsink-ambient, and top-case-ambient thermal resistances, respectively. $\Theta_{\text {solder }}$ and $\Theta_{T I M}$ denote the thermal resistances of the solder and thermal interface material (TIM) layers, respectively.

$T_{t}=\frac{P \Theta_{t a}\left(\Theta_{j c}+\Theta_{\text {solder }}+\Theta_{v i a}+\Theta_{T I M}+\Theta_{h a}\right)}{\Theta_{j t}+\Theta_{t a}+\Theta_{j c}+\Theta_{\text {solder }}+\Theta_{v i a}+\Theta_{T I M}+\Theta_{h a}}+T_{a}$

The thermal resistances from the top-case to the ambient and from the heatsink to the ambient, $\Theta_{t a}$ and $\Theta_{h a}$, are temperature-dependent, and thus, it is difficult to directly obtain their values. Hence, an equivalent top-case to ambient thermal resistance $\psi_{t a}$ is introduced, which is defined as

$$
\psi_{t a}=\frac{T_{t}-T_{a}}{P}
$$

where $P$ represents the total power loss generated inside the chip. Substituting (40) to (41) yields

$$
\begin{aligned}
& \psi_{t a}=\frac{\Theta_{t a}\left(\Theta_{j c}+\Theta_{\text {solder }}+\Theta_{v i a}+\Theta_{T I M}+\Theta_{h a}\right)}{\Theta_{j t}+\Theta_{t a}+\Theta_{j c}+\Theta_{\text {solder }}+\Theta_{v i a}+\Theta_{T I M}+\Theta_{h a}} \\
&=\left(\frac{\Theta_{j t} / \Theta_{t a}+1}{\Theta_{j c}+\Theta_{\text {solder }}+\Theta_{v i a}+\Theta_{T I M}+\Theta_{h a}}+\frac{1}{\Theta_{t a}}\right)^{-1} \\
& \Rightarrow \Theta_{v i a}=\psi_{t a}\left(1+\Theta_{j t} / \Theta_{t a}\right)-\Theta_{j c}-\Theta_{\text {solder }}-\Theta_{T I M}-\Theta_{h a}
\end{aligned}
$$

It is seen from (42) that the thermal resistance of a PCB via array is proportional to the equivalent top-case-ambient thermal resistance $\psi_{t a}$. If other thermal resistances stay the same, then $\psi_{t a}$ can be used to reflect the thermal resistance of PCB vias with different designs.

Each diode in Fig. 21(b) is controlled to generate a 2.8-W power loss. When the steady state is reached, the temperature contour of the experimental setup is captured by an infrared camera, as shown in Fig. 23. Then, the top-case temperature and the equivalent top-case-ambient thermal resistance of each diode can be obtained, as listed in Table II. Without solder filled, the via diameter of $0.25 \mathrm{~mm}$ helps the diode achieve the lowest top-case temperature and the smallest equivalent top-case-ambient thermal resistance. When the vias are filled up with high-thermal-conductivity solder, then the via array with $\phi=0.8 \mathrm{~mm}$ has the minimum thermal resistance. Furthermore, it is seen that the via array in Pattern II has a lower thermal resistance than Pattern I when other parameters remain the same. These trends agree pretty well with the theoretical analysis done in Section II.

The experimental setup for the thermal measurements of PCB pads is shown in Fig. 21(c). As can be seen, the diodes are mounted on four 2-layer PCBs (70- $\mu \mathrm{m}$ copper thickness for each layer) with different sizes of copper pads. Each diode is connected to a dc power source, and thus the diode is able to generate power losses, which are further conducted to the thermal pad and dissipated to the ambient by natural convection. A voltage meter and a current meter are used to measure the power loss generated by each diode. For each measurement, the power losses of the four diodes are controlled to the same value. The steady-state thermal images of the diodes are captured for different power losses (i.e., $P=0.5 \mathrm{~W}$ and $P=1 \mathrm{~W}$ ) and different sizes of copper pads, as shown in Fig. 24.

Fig. 25 (a) and (b) presents the measured and calculated junction and top-case temperatures in the two cases of $P=$ $0.5 \mathrm{~W}$ and $P=1 \mathrm{~W}$. As can be seen, there is a significant topcase temperature difference between the existing model [14], [31] and the measurements, especially when the copper pad radius is small. In contrast, the proposed model in Section III is able to more accurately predict the top-case temperature.

The maximum operating junction temperature of the selected diode VS-6EWL06FN-M3 is $175{ }^{\circ} \mathrm{C}$ [49]. For reliability reasons, the maximum junction temperature $T_{\text {jmax }}$ should be smaller than a lower value, e.g., $T_{j \max }=125^{\circ} \mathrm{C}$. In this case, the required minimum copper radius can be found, as illustrated in Fig. 25 (a) and (b). If the maximum power loss of the diode is $0.5 \mathrm{~W}$, then the minimum copper radius $r_{e}$ is $2.8 \mathrm{~mm}$ based on the proposed model. In contrast, the existing model provides a minimum copper radius of $6.1 \mathrm{~mm}$, which corresponds to an around $375 \%$ increase for the copper pad area compared to the design of $r_{e}=2.8 \mathrm{~mm}$. If the maximum power loss of the diode is $1 \mathrm{~W}$, then the minimum copper radius $r_{e}$ is $5.9 \mathrm{~mm}$ according to the proposed model. However, the existing model shows the minimum $r_{s}$ is $9.7 \mathrm{~mm}$. That means a $170 \%$ increase for the copper pad area.

Substitute the measured top-case temperatures into (32), and then the thermal resistance from the board to the ambient can be derived, as shown in Fig. 25(c). To make a comparison, the results from the existing model and the proposed model (24) are shown in Fig. 25(c) as well. It can be seen that there is a remarkable error between the measurements and the results from the existing model. However, a good agreement can be achieved between the measurements and the results from the proposed model. 


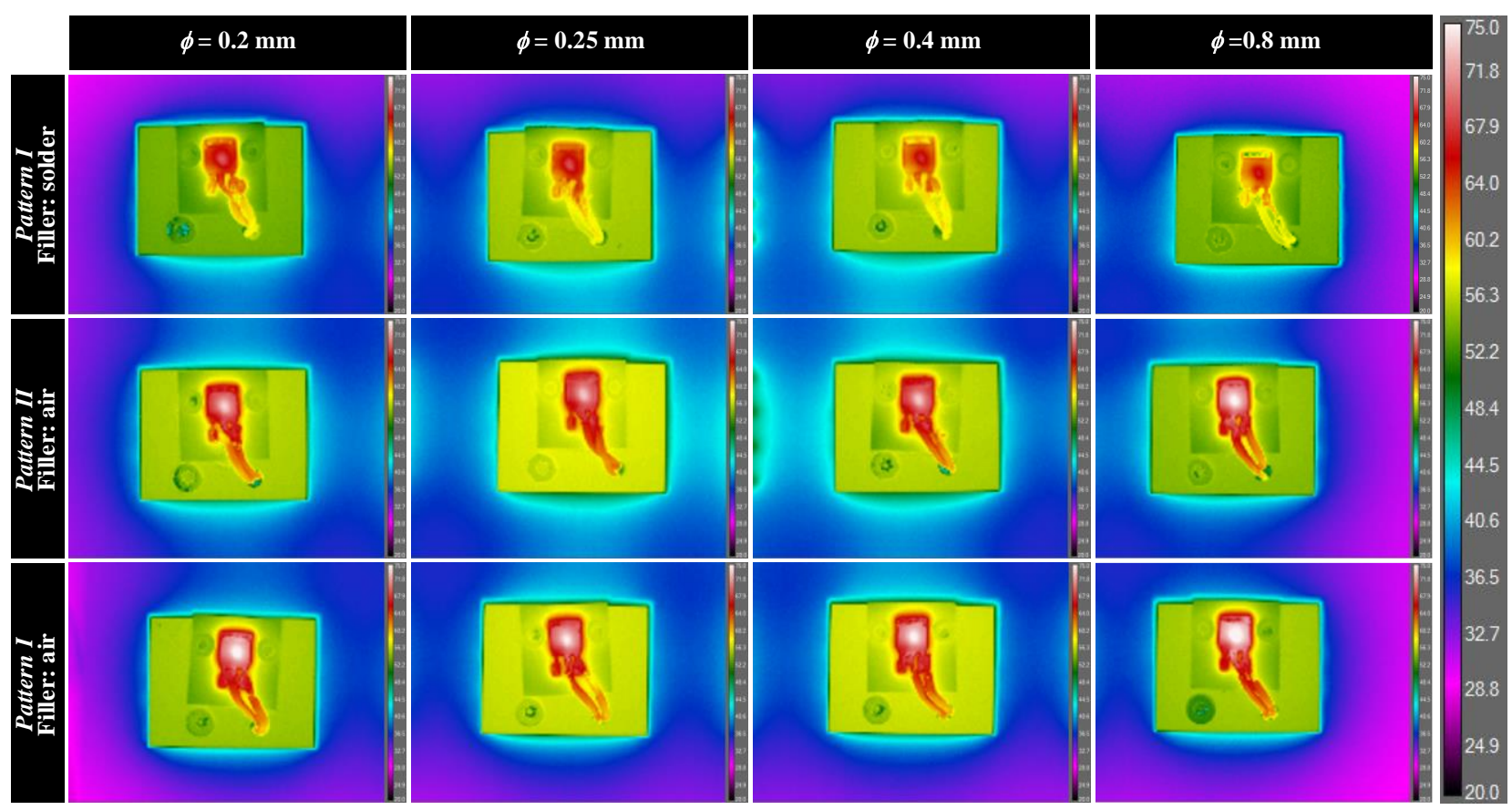

Fig. 23. Thermal image of the experimental setup when each diode generates a power loss of $2.8 \mathrm{~W}$

TABLE II

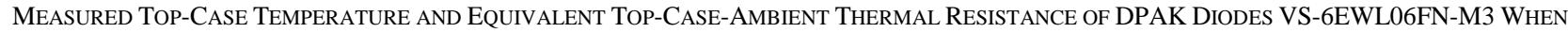
THE COOLING CONDITIONS, POWER LOSS AND AMBIENT TEMPERATURE ARE SPECIFIED AS Fig. 22.

\begin{tabular}{llllllllll}
\hline \hline \multirow{2}{*}{ Pattern } & Filler & \multicolumn{2}{l}{$\phi=0.2 \mathrm{~mm}$} & \multicolumn{2}{l}{$\phi=0.25 \mathrm{~mm}$} & \multicolumn{2}{l}{$\phi=0.4 \mathrm{~mm}$} & \multicolumn{2}{l}{$\phi=0.8 \mathrm{~mm}$} \\
\cline { 3 - 11 } & material & $T_{t}$ & $\psi_{t a}$ & $T_{t}$ & $\psi_{t a}$ & $T_{t}$ & $\psi_{t a}$ & $T_{t}$ & $\psi_{t a}$ \\
\hline Pattern I & Solder & $68.2^{\circ} \mathrm{C}$ & $15.43^{\circ} \mathrm{C} / \mathrm{W}$ & $67.3^{\circ} \mathrm{C}$ & $15.1^{\circ} \mathrm{C} / \mathrm{W}$ & $66.4^{\circ} \mathrm{C}$ & $14.8^{\circ} \mathrm{C} / \mathrm{W}$ & $65.7^{\circ} \mathrm{C}$ & $14.5^{\circ} \mathrm{C} / \mathrm{W}$ \\
\hline Pattern II & Air & $72.9^{\circ} \mathrm{C}$ & $17.1^{\circ} \mathrm{C} / \mathrm{W}$ & $72.4^{\circ} \mathrm{C}$ & $16.9^{\circ} \mathrm{C} / \mathrm{W}$ & $72.6^{\circ} \mathrm{C}$ & $17.0^{\circ} \mathrm{C} / \mathrm{W}$ & $74.8^{\circ} \mathrm{C}$ & $17.8^{\circ} \mathrm{C} / \mathrm{W}$ \\
\hline Pattern I & Air & $75.2^{\circ} \mathrm{C}$ & $17.9^{\circ} \mathrm{C} / \mathrm{W}$ & $74.1^{\circ} \mathrm{C}$ & $17.5^{\circ} \mathrm{C} / \mathrm{W}$ & $74.6{ }^{\circ} \mathrm{C}$ & $17.7{ }^{\circ} \mathrm{C} / \mathrm{W}$ & $76.5^{\circ} \mathrm{C}$ & $18.4^{\circ} \mathrm{C} / \mathrm{W}$ \\
\hline \hline
\end{tabular}

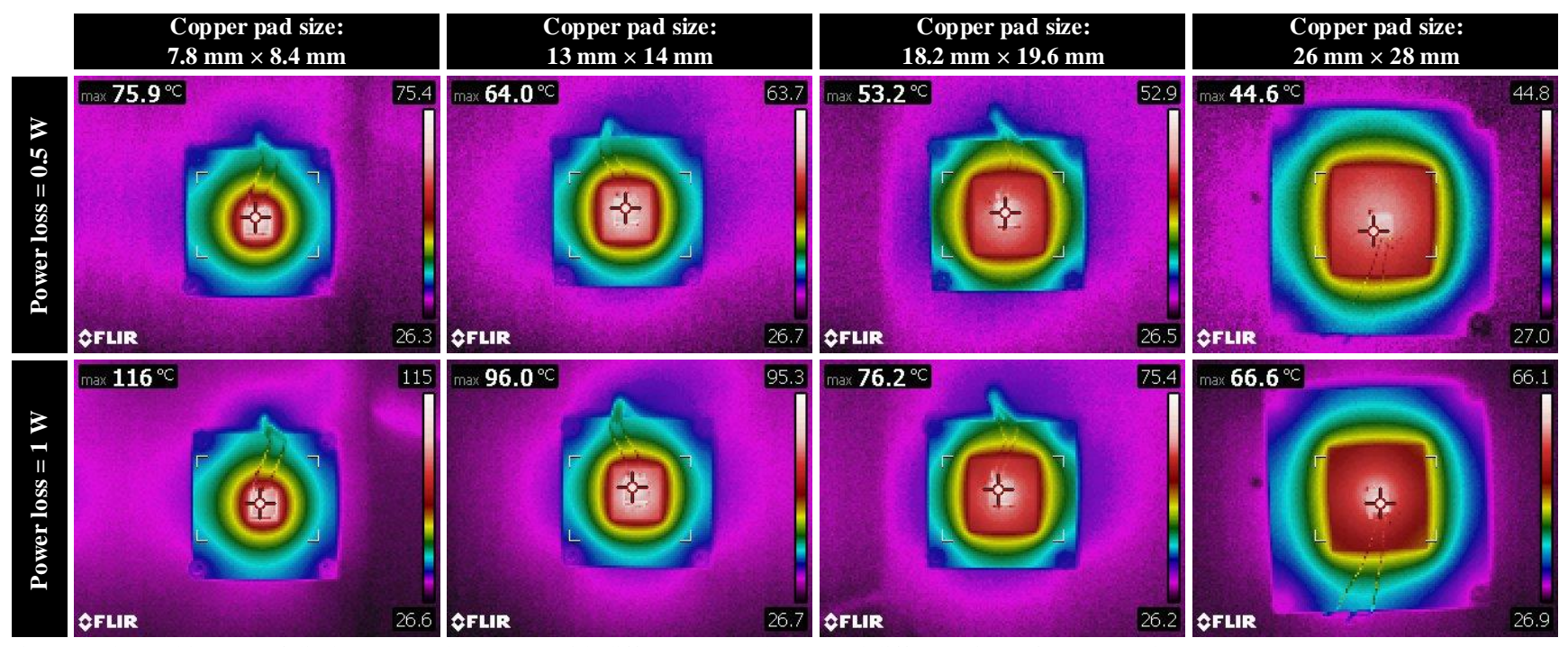

Fig. 24. Thermal images of diodes mounted on PCBs with different power losses and different sizes of copper pads. 


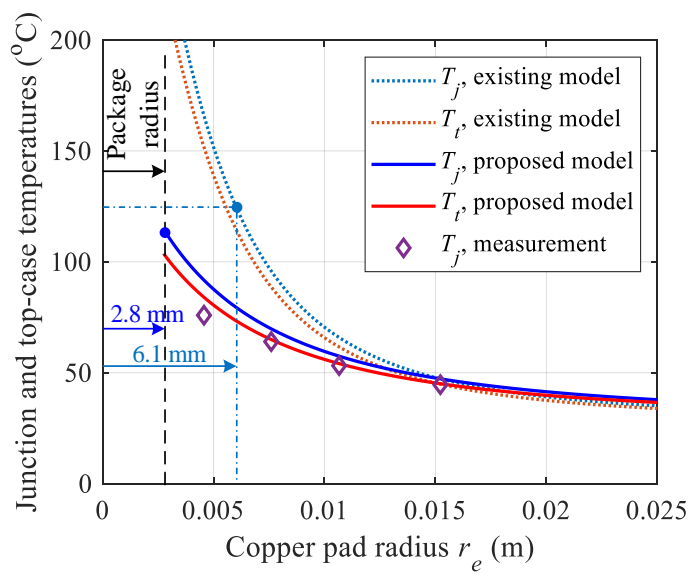

(a)

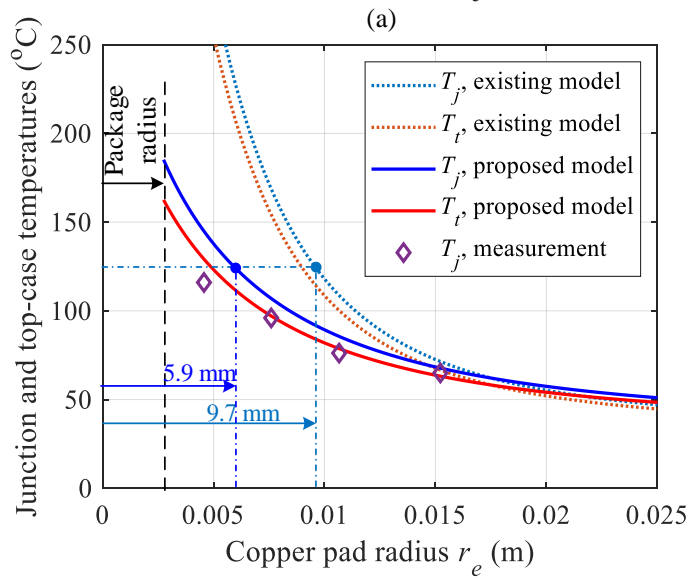

(b)

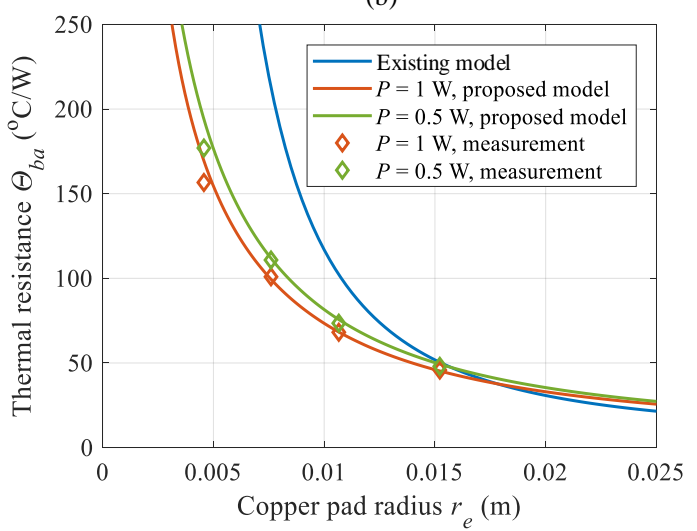

(c)

Fig. 25. Comparison of the junction and top-case temperatures between measurements and calculations when (a) $0.5-\mathrm{W}$ and (b) $1-\mathrm{W}$ power losses are generated inside the diode. (c) Comparison of the board-ambient thermal resistances obtained from the measurements, the existing model [14], [31] and the proposed model.

\section{CONCLUSIONS}

This paper proposes two analytical thermal resistance models and two design optimization methods for PCB vias and thermal pads. CFD simulations and experimental measurements verify the developed thermal models and optimal designs.

1) When other PCB parameters are determined, the viato-via spacing should be designed possibly small, and there exists an optimal via diameter which can help to achieve the minimum thermal resistance for PCB vias;
2) Both the via layout of Pattern II and solder filling contribute to further reductions to the thermal resistance of PCB vias;

3) The existing analytical thermal resistance model for PCB pads overestimates the junction temperatures of SMDs, whereas the proposed model enables a more accurate junction temperature prediction.

Therefore, the proposed thermal models enable engineers to fast and easily optimize the design of PCB vias and thermal pads.

\section{REFERENCES}

[1] E. A. Jones, F. F. Wang, and D. Costinett, "Review of commercial $\mathrm{GaN}$ power devices and $\mathrm{GaN}$-based converter design challenges," IEEE J. Emerging Sel. Topics Power Electron., vol. 4, no. 3, pp. 707719, Sep. 2016.

[2] J. Roberts, "Maximizing GaN power transistor performance with embedded packaging," in Proc. Appl. Power Electron. Conf. Expo. (APEC), 2015, pp. 1-14.

[3] S. Song, S. Munk-Nielsen, C. Uhrenfeldt, and I. Trintis, "Failure mechanism analysis of a discrete $650 \mathrm{v}$ enhancement mode $\mathrm{GaN}-\mathrm{on}-\mathrm{Si}$ power device with reverse conduction accelerated power cycling test," in Proc. 2017 IEEE Applied Power Electronics Conference and Exposition (APEC), Mar. 2017, pp. 756-760.

[4] Y. Lei, C. Barth, S. Qin, W. C. Liu, I. Moon, A. Stillwell, D. Chou, T. Foulkes, Z. Ye, Z. Liao, and R. Pilawa-Podgurski, "A 2 kW, singlephase, 7-level flying capacitor multilevel inverter with an active energy buffer," IEEE Trans. Power Electron., vol. 32, no. 11, pp. 8570-8581, Nov 2017.

[5] B.S. McCoy, M.A. Zimmermann, "Performance Evaluation and Reliability of Thermal Vias", in Proc. Appl. Power Electron. Conf. Expo. (APEC), 2004, pp. 1250-1256.

[6] H. Wang, M. Liserre, F. Blaabjerg, P. Rimmen, J. Jacobsen, T. Kvisgaard, and J. Landkildehus, "Transitioning to physics-of-failure as a reliability driver in power electronics," IEEE J. Emerg. Sel. Topics Power Electron., vol. 2, no. 1, pp. 97-114, Mar. 2014.

[7] Y. Ning, M. H. Azarian and M. Pecht, "Effects of Voiding on Thermomechanical Reliability of Copper-Filled Microvias: Modeling and Simulation," IEEE Trans. Device Mater. Rel., vol. 15, no. 4, pp. 500-510, Dec. 2015.

[8] P. Wild, T. Grozinger, D. Lorenz, and A. Zimmermann, "Void Formation and Their Effect on Reliability of Lead-Free Solder Joints on MID and PCB Substrates," IEEE Trans. Rel., vol. 66, no. 4, pp. 1229-1237, Dec. 2017.

[9] B. Heinz, "Heat management of circuit boards," Wurth Elektronik Tec. Report, pp. 1-6, 2011. [online]. Available: https://www.weonline.com/web/en/index.php/show/media/04_leiterplatte/2011_2/rel aunch/produkte 5/heatsink/neu 2011/TecReport 01_2011_EN_S.pd f

[10] H. Wang, M. Liserre, and F. Blaabjerg, "Toward reliable power electronics: Challenges, design tools, and opportunities," IEEE Ind. Electron. Mag., vol. 7, no. 2, pp. 17-26, Jun. 2013.

[11] S. Gautam, F. Musavi, D. Wager, and M. Edington, "A comparison of thermal vs. patterns used for thermal management in power converter," in Proc. Energy Conversion Congress and Exposition (ECCE), 15- 19 Sept. 2013, pp. $2214-2218$.

[12] C. Yu, C. Buttay, and E. Laboure, "Thermal Management and Electromagnetic Analysis for GaN Devices Packaging on DBC Substrate," IEEE Trans. Power Electron., vol. 32, no. 2, pp. 906-910, Feb. 2017.

[13] P. L. Brohlin, M. Beheshti, S. Bahl, S. Dusmez, and T. Chen, "Designing Reliable and High-Density Power Supplies with GaN," in Proc. Appl. Power Electron. Conf. Expo. (APEC), 2018, pp. 1-88.

[14] ON Semiconductor, "Application Note: A Quick PCB Thermal Calculation for Power Electronic Devices with Exposed Pad Packages," pp. 1-14, Oct. 2017. [online]. Available: http://www.onsemi.com/pub/Collateral/AND9596-D.PDF 
[15] GaN Systems, "Application Note: PCB Thermal Design Guide for GaN Enhancement Mode Power Transistors,” pp. 1-20, Mar. 2015. [online]. Available: http://www.gansystems.com/whitepapers.php

[16] Cree, "Product Design Guide: Optimizing PCB Thermal Performance for Cree ${ }^{\circledR}$ XLamp ${ }^{\circledR}$ LEDs," Product Design Guide, [online]. Available: http://www.cree.com/ledcomponents/media/documents/XLamp_PCB_Thermal.pdf

[17] "AN-2020 Thermal Design By Insight, Not Hindsight," Texas Instruments Application Report, Apr. 2013. [online]. Available: http://www.ti.com/lit/an/snva419c/snva419c.pdf

[18] S. Kummerl, and H. Nguyen, "PowerPAD"M Thermally Enhanced Package," Texas Instruments Application Report, pp. 1-30, Jul. 2018, [online] Available: http://www.ti.com/lit/an/spra953c/spra953c.pdf

[19] T. A. Asghari, "PCB Thermal Via Optimization using Design of Experiments", in Proc. 10th Intersociety Conference on Thermal and Thermomechanical Phenomena in Electronics Systems, June 2006.

[20] N. Kafadarova, and A. Andonova, "PCB Thermal Design Improvement Through Thermal Vias", in Proc. 8th WSEAS International Conference on Circuits, Systems, Electronics, Control \& Signal Processing, Spain, December 2009.

[21] H. W Shin, H. S. Lee, and S. B. Jung, "Analysis on Thermal Resistance of LED Module with Various Thermal Vias", in Proc. International Symposium on the Physical and Failure Analysis of Integrated Circuits (IPFA), 2011, pp.1-4.

[22] R. Li, "Optimization of Thermal Via Design Parameters Based on an Analytical Thermal Resistance Model," in Proc. 6th InterSociety Conference on Thermal and Thermomechanical Phenomena in Electronic Systems (ITherm'98), Seattle, 27-30 May 1998, pp. 475480.

[23] C. Negrea, P. Svasta, "Modeling of Thermal Via Heat Transfer Performance for Power Electronics Cooling", in Proc. 17th International Symposium on Design and Technology in Electronic Packaging, Oct. 2011.

[24] S. Zhang, E. Laboure, D. Labrousse, and S. Lefebvre, "Thermal management for $\mathrm{GaN}$ power devices mounted on PCB substrates," in Proc. IEEE International Workshop on Integrated Power Packaging (IWIPP), 2017, pp. 1-5.

[25] B. Guenin, "Thermal Vias-A Packaging Engineer's Best Friend," Electronics Cooling, vol. 10, no. 3, Aug., 2004.

[26] S. Gurrum, and M. Romig, "Using Thermal Calculation Tools for Analog Components," TI Application Report SLUA566, pp. 1-13, Sep. 2010.

[27] Y. Koito, Y. Kubo, and T. Tomimura, "Numerical Analysis of Printed Circuit Board with Thermal Vias: Heat Transfer Characteristics under Nonisothermal Boundary Conditions," Journal of Electronics Cooling and Thermal Control, vol. 3., pp. 136-143, 2013

[28] W. Nakayama, "Heat Conduction in Printed Circuit Boards: A Mesoscale Modeling Approach," ASME Journal of Electronic Packaging, vol. 130, no. 4, pp. 1-10, 2008.

[29] M. Ouhab, Z. Khatir, A. Ibrahim, J. Ousten, R. Mitova and M. X. Wang, "New Analytical Model for Real-Time Junction Temperature Estimation of Multi-Chip Power Module Used in a Motor Drive," IEEE Trans. Power Electron., vol. PP, no. 99, pp. 1-1. doi: 10.1109/TPEL.2017.2736534.

[30] C. Sciascera, P. Giangrande, L. Papini, C. Gerada, and M. Galea, "Analytical thermal model for fast stator winding temperature prediction," IEEE Trans. Ind. Electron., vol. 64, no. 8, pp. 6116-6126, Aug. 2017.

[31] B. Guenin, "Heat Spreading Calculations Using Thermal Circuit Elements," Electronics Cooling, vol. 14, no. 3, Aug., 2008.

[32] Wikipedia, "Thermal conductivity," [online]. Available: https://en.wikipedia.org/wiki/Thermal_conductivity. [Accessed Jan. 2019].

[33] K. Azar, and J. E. Graebner, "Experimental Determination of Thermal Conductivity of Printed Wiring Boards," in Proc. the Twelfth IEEE SEMI-THERM Symposium, 1996, pp. 169-182.

[34] "Air - Thermal Conductivity," [online]. Available: https://www.engineeringtoolbox.com/air-properties-viscosityconductivity-heat-capacity-d_1509.html. [Accessed Jan.2019].

[35] Wikipedia, "List of thermal conductivities," [online]. Available: https://en.wikipedia.org/wiki/List of thermal conductivities

[36] Wikipedia, "Solder," [online]. Available: https://en.wikipedia.org/wiki/Solder. [Accessed Jan.2019].
[37] L. Lambert, "IPC-6012 A Review, What is it? and Who Uses it?" [online], Available: $\quad$ https://www.eptac.com/wpcontent/uploads/2015/02/eptac 03 18 15-1.pdf. [Accessed Jan.2019].

[38] C. Yunus, and J. Afshin. Heat and mass transfer: fundamentals and applications. New Delhi, India: Tata Mcgraw Hill; 2011.

[39] J. Adam, "PCB Modelling Refresher," Mentor, May 2002. [online], Available: $\quad$ http://webparts.mentor.com/flotherm/support/ supp/mm/pcb_modelling/.

[40] G. A. Luiten, "Heat spreading from a small source on a thin plate, Semitherm 28, San Jose, 2012.

[41] G. A. Luiten, "Heat spreading in a thin longitudinal fin," Microelectron. J. vol. 45, no. 5, pp. 539-546, May 2014.

[42] R. E. Simons, "Simplified Formula for Estimating Natural Convection Heat Transfer Coefficient on a Flat Plate," Electronics Cooling, vol. 7, no. 3, Aug. 2001.

[43] J. P. Holman. Heat transfer, $10^{\text {th }}$ edition. New York, McGraw-Hill, 2008

[44] JEDEC Standard, "JESD51-2A: Integrated Circuits Thermal Test Method Environmental Conditions - Natural Convection (Still Air)," pp. 1-14, Jan. 2008.

[45] "Cree XLamp LEDs Solder Joint Reliability Study," Cree Support Document, [online.] Available: https://www.cree.com/ledcomponents/media/documents/Solder-Joint-Reliability.pdf. [Accessed Jan. 2019].

[46] "Fixed-point iteration," Wikipedia, [online]. Available: https://en.wikipedia.org/wiki/Fixed-point_iteration. [Accessed Feb. 2019].

[47] “Aitken's delta-squared process," Wikipedia, [online]. Available: https://en.wikipedia.org/wiki/Aitken\%27s_delta-squared_process. [Accessed Feb. 2019].

[48] "Steffensen's method," Wikipedia, [online]. Available: https://en.wikipedia.org/wiki/Steffensen\%27s method. [Accessed Feb. 2019].

[49] Vishay Semiconductors, VS-6EWL06FN-M3 datasheet, [online]. Available: https://www.vishay.com/docs/93502/vs-6ewl06fn-m3.pdf. [Accessed Feb. 2019].

[50] "ANSYS Icepak," [online]. Available: https://www.ansys.com/engb/products/electronics/ansys-icepak. [Accessed Feb. 2019].

[51] "Overview of Using the Solver," [online]. Available: https://www.sharcnet.ca/Software/Ansys/16.2.3/enus/help/flu_ug/flu_ug_sec_solve_using_overview.html. [Accessed Feb. 2019].

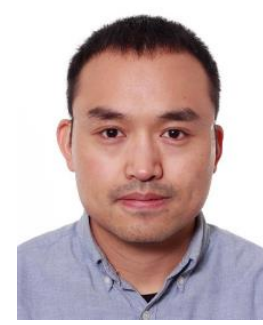

Yanfeng Shen (S'16-M'18) received the B.Eng. degree in electrical engineering and automation and the M.Sc. degree in power electronics from Yanshan University, Qinhuangdao, China, in 2012 and 2015, respectively, and the Ph.D. degree in power electronics from Aalborg University, Aalborg, Denmark, in 2018.

$\mathrm{He}$ is currently a Postdoctoral Research Associate with the University of Cambridge, UK. $\mathrm{He}$ worked as an Intern with $\mathrm{ABB}$ Corporate Research Center, Beijing, China, in 2015. His research interests include the reliability of power electronics, EV and PV inverters, and applications of $\mathrm{SiC}$ and $\mathrm{GaN}$ devices.

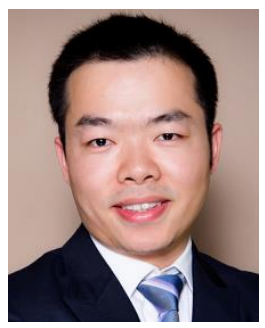

Huai Wang (M'12-SM'17) received the B.E. degree in electrical engineering, from Huazhong University of Science and Technology, Wuhan, China, in 2007 and the Ph.D. degree in power electronics, from the City University of Hong Kong, Hong Kong, in 2012. He is currently an Associate Professor at the Center of Reliable Power Electronics (CORPE), and Vice Leader of Efficient and Reliable Power Electronics Research Program at Aalborg University, Aalborg, Denmark, and. He was a Visiting Scientist with the ETH Zurich, Switzerland, from Aug. to Sep. 2014, and with the Massachusetts Institute of Technology (MIT), USA, from Sep. to Nov. 2013. 
He was with the ABB Corporate Research Center, Switzerland, in 2009. His research addresses the fundamental challenges in modelling and validation of power electronic component failure mechanisms, and application issues in system-level predictability, condition monitoring, circuit architecture, and robustness design.

Dr. Wang received the Richard M. Bass Outstanding Young Power Electronics Engineer Award from the IEEE Power Electronics Society in 2016, and the Green Talents Award from the German Federal Ministry of Education and Research in 2014. He is currently the Chair of IEEE PELS/IAS/IE Chapter in Denmark. He serves as an Associate Editor of IET Electronics Letters, IEEE JOURNAL OF EMERGING AND SELECTED TOPICS IN POWER ELECTRONICS, and IEEE TRANSACTIONS ON POWER ELECTRONICS.

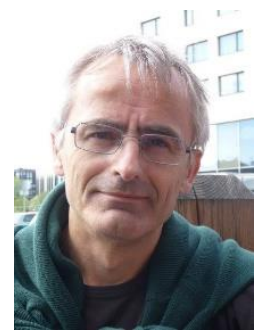

Frede Blaabjerg (S'86-M'88-SM'97-F'03) was with ABB-Scandia, Randers, Denmark, from 1987 to 1988. From 1988 to 1992, he got the PhD degree in Electrical Engineering at Aalborg University in 1995. He became an Assistant Professor in 1992, an Associate Professor in 1996, and a Full Professor of power electronics and drives in 1998. From 2017 he became a Villum Investigator. He is honoris causa at University Politehnica Timisoara (UPT), Romania and Tallinn Technical University (TTU) in Estonia.

His current research interests include power electronics and its applications such as in wind turbines, PV systems, reliability, harmonics and adjustable speed drives. He has published more than 600 journal papers in the fields of power electronics and its applications. He is the co-author of four monographs and editor of ten books in power electronics and its applications.

He has received 30 IEEE Prize Paper Awards, the IEEE PELS Distinguished Service Award in 2009, the EPE-PEMC Council Award in 2010, the IEEE William E. Newell Power Electronics Award 2014 and the Villum Kann Rasmussen Research Award 2014. He was the Editor-in-Chief of the IEEE TRANSACTIONS ON POWER ELECTRONICS from 2006 to 2012. He has been Distinguished Lecturer for the IEEE Power Electronics Society from 2005 to 2007 and for the IEEE Industry Applications Society from 2010 to 2011 as well as 2017 to 2018. In 20192020 he serves the President of IEEE Power Electronics Society. He is VicePresident of the Danish Academy of Technical Sciences too.

He was nominated in 2014-2018 by Thomson Reuters to be between the most 250 cited researchers in Engineering in the world.

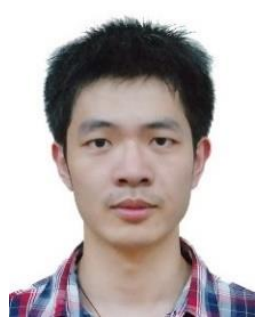

Hui Zhao (S'14) received the bachelor and master degrees from Huazhong University of Science and Technology, China, and the Ph.D. degree from the Universality of Florida, USA, in 2018. He had a summer internship at General Electric (GE) Global Research Center Shanghai in 2013. He is now a post-doctoral research associate in the University of Cambridge. He has authored and coauthored several IEEE conference and transaction papers.

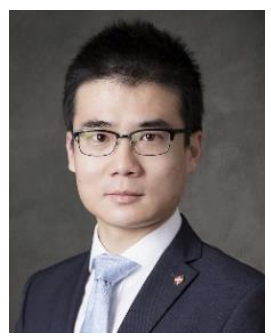

Teng Long (M'13) received the B.Eng. degree from Huazhong University of Science and Technology, China, the first class B.Eng. (Hons.) degree from the University of Birmingham, UK in 2009, and the Ph.D. degree from the University of Cambridge, UK in 2013.

Until 2016, he was a Power Electronics Engineer with the General Electric (GE) Power Conversion business in Rugby, UK. $\mathrm{He}$ is currently a Lecturer with the University of Cambridge. His research interests include power electronics, electrical machines, and machine drives. Dr Long is a Chartered Engineer (CEng) registered with the Engineering Council in the UK. 